\title{
Inflation and relative price variability in the euro area: evidence from a panel threshold model
}

\author{
Dieter Nautz \\ (Goethe University Frankfurt) \\ Juliane Scharff \\ (Goethe University Frankfurt)
}

Discussion Paper

Series 1: Economic Studies

No $14 / 2006$

Discussion Papers represent the authors' personal opinions and do not necessarily reflect the views of the Deutsche Bundesbank or its staff. 


$\begin{array}{ll}\text { Editorial Board: } & \text { Heinz Herrmann } \\ & \text { Thilo Liebig } \\ & \text { Karl-Heinz Tödter }\end{array}$

Deutsche Bundesbank, Wilhelm-Epstein-Strasse 14, 60431 Frankfurt am Main, Postfach 1006 02, 60006 Frankfurt am Main

Tel +49 69 9566-1

Telex within Germany 41227, telex from abroad 414431, fax +49695601071

Please address all orders in writing to: Deutsche Bundesbank,

Press and Public Relations Division, at the above address or via fax +49 69 9566-3077

Reproduction permitted only if source is stated.

ISBN 3-86558-143-9 (Printversion)

ISBN 3-86558-144-7 (Internetversion) 


\begin{abstract}
In recent macroeconomic theory, relative price variability (RPV) generates the central distortions of inflation. This paper provides first evidence on the empirical relation between inflation and RPV in the euro area focusing on threshold effects of inflation. We find that expected inflation significantly increases RPV if inflation is either very low (below $-1.38 \%$ p.a.) or very high (above $5.94 \%$ p.a.). In the intermediate regime, however, expected inflation has no distorting effects which supports price stability as an outcome of optimal monetary policy.

Keywords: Inflation, Relative Price Variability, Panel Threshold Models

JEL classification: E31, C23
\end{abstract}




\section{Non Technical Summary}

There is now a general consensus that inflation produces welfare costs and price stability should be the prior goal of monetary policy. In this regard, recent macroeconomic theory emphasizes the distorting impact of inflation on the information content of nominal prices. If inflation causes a suboptimal adjustment of goods prices due to price adjustment costs or imperfect information, then inflation increases relative price variability (RPV), reduces the transparency of the relative price mechanism and impedes the efficient allocation of resources.

The bulk of the empirical literature deals with the linear relationship between inflation and RPV implying that the marginal impact of inflation on RPV does not depend on the inflation level. However, the impact of inflation on the economy might be non-linear. As the empirical literature on the link between inflation and long-term growth shows, the effect of inflation on growth changes if inflation is above certain threshold values of inflation. Moreover, the European Central Bank, for example, defines price stability as an inflation rate below but close to the critical level of $2 \%$.

Accounting for a potential non-linear impact of inflation on the economy, this study provides evidence on the empirical relation between inflation and RPV in the euro area focusing on threshold effects of inflation. The application of panel threshold models allows to test for the number of inflation thresholds and to estimate both the threshold levels as well as the marginal impact of inflation on RPV for the various threshold levels of inflation. The empirical results show that threshold effects of inflation can be confirmed for the inflation-RPV nexus in the euro area. In addition to a linear impact of unexpected inflation, there is strong evidence in favor of a non-linear influence of expected inflation on RPV. We find that expected inflation significantly increases RPV if price changes are either clearly negative $(<-1.4 \%$ p.a.) or very high $(>5.9 \%$ p.a. $)$. Between these two thresholds expected inflation has according to our estimations no real effects on the economy via its impact on RPV (but may have other effects). Therefore, threshold effects of inflation provide a further rational for the announcement of critical levels of inflation and inflation target zones. 


\section{Nicht technische Zusammenfassung}

Mittlerweile ist es nahezu unstrittig, dass Inflation volkswirtschaftliche Kosten verursacht und deshalb Preisstabilität das vorrangige Ziel moderner Geldpolitik sein muss. Begründet wird dies in der aktuellen makroökonomischen Theorie vor allem mit einem störenden Einfluss von Inflation auf den Informationsgehalt von Preisen. Werden bei Inflation die Güterpreise aufgrund von Preisänderungskosten oder unvollständiger Information nicht optimal angepasst, erhöht Inflation die relative Preisvariabilität (RPV), senkt die Transparenz des relativen Preismechanismus und verhindert so eine effiziente Allokation von Ressourcen.

Die empirische Literatur zum Einfluss von Inflation auf die Variabilität der relativen Preise unterstellte bislang stets einen linearen Zusammenhang, infolge dessen der marginale Effekt von Inflation auf die relative Preisvariabilität unabhängig vom Niveau der Inflationsrate ist. Doch Ergebnisse aus der empirischen Literatur zum Einfluss von Inflation auf das langfristige Wachstum zeigen, dass Inflation besonders schädlich ist, wenn sie bestimmte Schwellenwerte (Thresholds) überschreitet. Auch die Europäische Zentralbank sieht Preisstabilität als gewährleistet an, wenn die Preissteigerungsrate nahe aber unter dem kritischen Wert von 2\% liegt.

Diese Studie untersucht erstmals die empirische Relevanz von Schwellenwerten der Inflation für die Wirkung von Inflation auf die Variabilität der relativen Preise in der Eurozone mit Hilfe eines Panel-Threshold-Modells. Das Panel-Threshold-Modell ermöglicht dabei die Bestimmung der Anzahl der Schwellenwerte für Inflation, die Schätzung der Threshold-Höhe sowie die Schätzung des marginalen Einflusses der Inflation auf die relative Preisvariabilität in Abhängigkeit von der Inflationshöhe. Die Ergebnisse für die Eurozone zeigen, dass es neben einem linearen Zusammenhang zwischen unerwarteter Inflation und relativer Preisvariabilität auch einen nichtlinearen Zusammenhang zwischen der erwarteten Inflation und der relativen Preisvariabilität gibt. Insbesondere besitzt die erwartete Preisänderung nur dann einen positiven Einfluss auf die relative Preisvariabilität, wenn sie deutlich negativ (<-1.4\% p.a.) oder sehr hoch $(>5.9 \%$ p.a.) gewesen ist. Bei Inflationsraten, die zwischen diesen beiden Schwellenwerten liegen, erzeugt die erwartete Inflation nach unseren Rechnungen keine realen Effekte über ihren Einfluss auf die relative Preisvariabilität (was andere Effekte 
nicht ausschließt). Das Vorliegen von Schwellenwert-Effekten in der Wirkung von Inflation auf RPV liefert damit ein empirisches Argument für die Orientierung der Geldpolitik an Inflationszielen oder bestimmten Ober- und Untergrenzen für die Inflationsrate. 


\section{Contents}

1 Introduction 1

2 The linear relation between inflation and RPV in the euro area 4

2.1 Data . . . . . . . . . . . . . . . . . . . . . . 4

2.2 Inflation and RPV: the basic relationship . . . . . . . . . 8

2.3 Expected inflation versus unexpected inflation . . . . . . . . . . . . 9

3 The non-linear relation between inflation and RPV 11

4 The Panel-Threshold-Model 13

4.1 The single threshold model . . . . . . . . . . . . . . . . . . . 13

4.1.1 Estimation of a single threshold . . . . . . . . . . . . . . . 13

4.1.2 Testing for a threshold . . . . . . . . . . . . . . . . . 15

4.1.3 Confidence intervals for threshold estimate and slope coefficients 16

4.2 Multiple thresholds . . . . . . . . . . . . . . . . . . . . . . . . . . . 17

4.2.1 Estimating multiple thresholds . . . . . . . . . . . . . . 17

4.2 .2 Testing for the number of thresholds . . . . . . . . . . . . . 18

4.2 .3 Confidence Intervals . . . . . . . . . . . . . . . . . . . . . . 19

5 Inflation thresholds and RPV: Empirical results for the euro area 19

5.1 Model specification . . . . . . . . . . . . . . . . . . . . . . . 19

5.2 The number of inflation thresholds . . . . . . . . . . . . . 21

5.3 Estimating the inflation thresholds and the slope coefficients . . . . . . 23

6 Conclusion $\quad 24$

$\begin{array}{ll}\text { A Appendix } & 30\end{array}$

A.1 Data figures . . . . . . . . . . . . . . . . 30

A.2 Tables . . . . . . . . . . . . . . . . . . 33

A.2.1 Panel unit root tests . . . . . . . . . . . . . . 33

A.2.2 Expected core inflation and headline inflation as threshold variable 34

A.2.3 Unexpected inflation as threshold variable . . . . . . . . . . . 36 



\section{Inflation and Relative Price Variability in the Euro Area: Evidence from a Panel Threshold Model*}

\section{Introduction}

A large number of economic arguments point to the benefits of price stability and the welfare cost of inflation. Recent macroeconomic theory emphasizes the distorting impact of inflation on relative prices. In particular, standard new Keynesian dynamic general equilibrium models with staggered price setting support price stability as an outcome of optimal monetary policy mainly because inflation increases relative price variability (RPV), see e.g. Woodford (2003) or Gali (2003). ${ }^{1}$ In spite of the crucial role of inflation's impact on RPV, the empirical relevance of this relation is not very well researched. This paper contributes to the literature by providing new evidence on the relation between inflation and relative price variability in the European Monetary Union (EMU).

Since the influential paper by Parks (1978), several studies have provided evidence in favor of a significant impact of inflation on RPV for the US (see e.g. Grier and Perry (1996), Parsley (1996), Debelle and Lamont (1997), Jaramillo (1999), Chang and Cheng

${ }^{*}$ Department of Money and Macroeconomics, Mertonstr. 17, D-60054 Frankfurt am Main, Germany. e-mail: nautz@wiwi.uni-frankfurt.de; miszler@wiwi.uni-frankfurt.de. We thank Matei Demetrescu, Jörg Döpke, Uwe Hassler, Heinz Herrmann, Johannes Hoffmann, and the participants of the research seminar at the Bundesbank for helpful comments and suggestions. The research for this paper was partly conducted while Juliane Scharff was visiting the Economic Research Centre of the Deutsche Bundesbank. She is grateful for the research department's kind hospitality.

${ }^{1}$ Reducing the information content of nominal prices, inflation drives a wedge between marginal rates of transformation and substitution. Therefore, as Green (2005, p.132) put it, price dispersion is "the root of all evil" caused by inflation in these models. 
(2002)), as well as for various European countries for the pre-EMU period (Fielding and Mizen (2000), Silver and Ioannidis (2001), Konieczny and Skrzypacz (2005), Nautz and Scharff (2005)). While some allow for a specific role of expected and unexpected inflation, a common feature of all these contributions is that they restrict the attention to linear relationships implying that the marginal impact of inflation on RPV does not depend on the inflation level. However, the impact of inflation on the economy might be non-linear. Bruno and Easterly (1998), for example, showed that the effect of inflation on growth changes if inflation is above a threshold level of $40 \%$. Therefore, advancing on simple linear relationships, the use of threshold models seems a plausible first step for a deeper analysis of the relation between inflation and RPV.

A first attempt to model a non-linear relation between inflation and RPV can be found in Caglayan and Filiztekin (2003) who consider the inflation-RPV nexus for Turkish provinces. In Turkey there has been an obvious break in the inflation process around 1976. Therefore, Caglayan and Filiztekin (2003) simply divide the sample in a high and a low inflation period and estimate the RPV equation for the two periods separately. As a result, they neither estimate the threshold level of inflation nor the number of inflation regimes. Obviously, this approach should not be applied to recent euro area data where both the number of inflation thresholds as well as the exact threshold levels are unclear.

Moreover, in the threshold model applied by Caglayan and Filiztekin (2003) all Turkish provinces are, by construction, always in the same inflation regime. However, while the ECB's monetary policy is one and indivisible for the euro area as a whole, inflation differentials across EMU member countries have been considerable. Therefore, although there does not exist any regional monetary policy such that EMU member countries are always in the same monetary policy regime, the assumption that all countries are always in the same inflation regime is too restrictive. In the following, the number of inflation regimes will be determined empirically by the number of thresholds in the 
RPV-inflation equation.

With a view to these problems, the panel threshold model introduced by Hansen (1999, 2000 ) is a natural candidate for the analysis of the non-linear impact of inflation on RPV in the euro area. The application of the panel threshold model enables us to test for the number of inflation regimes and to estimate both the threshold levels as well as the marginal impact of inflation on RPV in the various regimes. Finally, the threshold model also allows different countries to be in different inflation regimes.

Threshold models have already been applied in the empirical literature on the link between inflation and long-term growth. In line with the earlier findings of Bruno and Easterly (1998), Tsionas and Christopoulos (2003) estimate a threshold effect of inflation in the inflation-growth relationship for the European Union. Cuaresma and Silgoner (2004) also investigate European data and identify even two thresholds for inflation and, thus, three different inflation regimes. A general conclusion of this literature is that the costs of inflation are particularly significant if inflation exceeds a certain threshold. Compared to usual inflation targets set in industrial countries, these thresholds are often found to be extremely high. For example, Cuaresma and Silgoner (2004) estimate the upper threshold of inflation to be around $16 \%$ p.a.

Our empirical results show that threshold effects of inflation can be confirmed for the inflation-RPV nexus in the euro area. In addition to a linear impact of unexpected inflation, there is strong evidence in favor of a hump-shaped effect of expected inflation. The strongest marginal impact on RPV is estimated for inflation rates below zero followed by a range of inflation where no significant effect of expected inflation on RPV prevails. Beyond the upper threshold there is again a positive effect of expected inflation. Interestingly, the estimated threshold level defining high inflation ranges between $3 \%$ and $6 \%$ p.a. In this respect, our empirical results obtained for the relation between inflation and RPV support the proposition that price stability should be the outcome of optimal monetary policy. 
The paper is organized as follows: Section 2 introduces the data and the RPV measure based on the harmonized index of consumer prices and provides first evidence on the linear relation between inflation and RPV in the euro area. We discuss the role of expected versus unexpected inflation and determine core inflation as the relevant inflation measure for the inflation-RPV analysis. The empirical literature on a non-linear impact of inflation on RPV is reviewed in Section 3 while Section 4 describes the econometrics of the panel threshold model by Hansen $(1999,2000)$. The empirical results of the panel threshold analysis for the euro area are presented in Section 5. Section 6 gives a brief summary of our main results and offers some conclusions.

\section{The linear relation between inflation and RPV in the euro area}

\subsection{Data}

The following empirical analysis of the link between inflation and RPV in the euro area employs monthly data for various subcategories of the harmonized index of consumer prices (HICP) provided by the Eurostat database. In the member states of the European Monetary Union, the harmonized indices of consumer prices provide a complete set of comparable and high-quality consumer price indices. Moreover, the ECB uses the euro area HICP to assess price stability. Therefore, the HICP is a natural choice for analyzing the inflation-RPV link for EMU members in a panel context. The data set contains seasonally adjusted data of twelve HICP subcategories for the EMU members Austria, Finland, France, Germany, Greece, Ireland, Italy, Netherlands, Portugal, and Spain. ${ }^{2}$ The data are available since January 1995 and our sample ends in December 2003.

\footnotetext{
2 The HICP subcategories are food and non-alcoholic beverages; alcoholic beverages, tobacco and narcotics; clothing and footwear; housing, water, electricity, gas and other fuels; furnishings, household equipment and routine maintenance of the house; health; transport; communication; recreation and culture; education; restaurants and hotels; miscellaneous goods and services. The sample does not contain Belgium and Luxembourg due to restricted data availability.
} 
Figure 1: Minimum and maximum of headline inflation

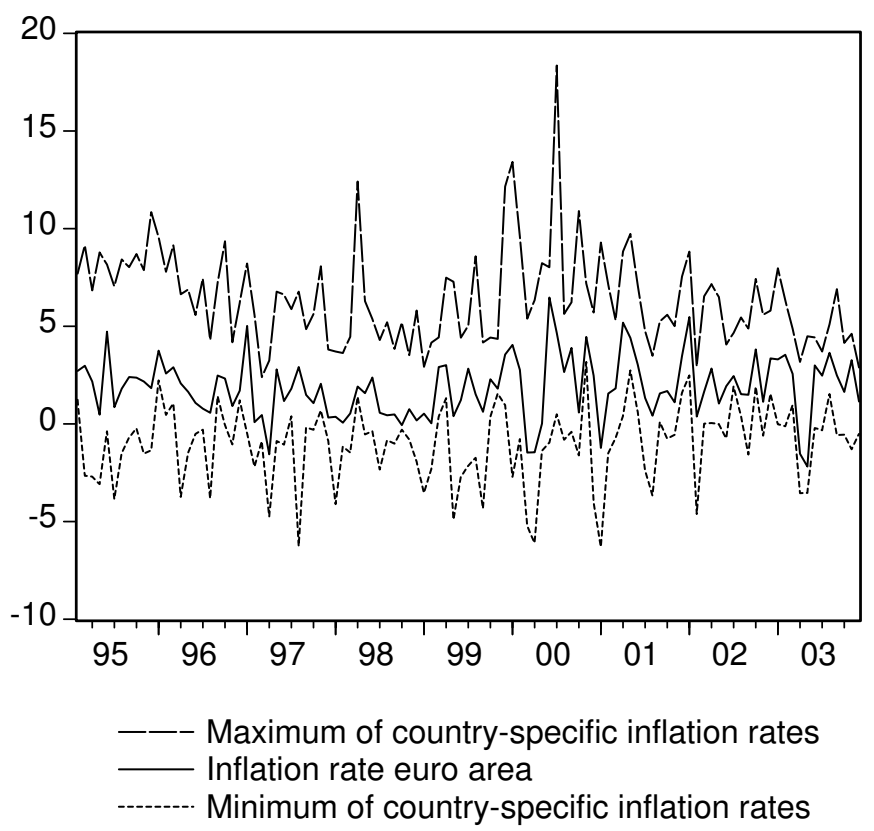

Notes: Annualized inflation rates (percentage points, seasonally adjusted) confer to the harmonized index of consumer prices, 1995.02-2003.12. Source: Eurostat. The generated time series for minimum (maximum) inflation show the minimum (maximum) of the national inflation rates across the EMU members.

Following the empirical literature (see e.g. Jaramillo (1999), Parsley (1996), Fielding and Mizen (2000)), the variability of relative price changes for country $i$ in period $t$ $\left(R P V_{i t}\right)$ is defined as the square root of the weighted sum of squared deviations of subcategory-inflation $\pi_{i j t}$ around the average inflation for country $i\left(\pi_{i t}\right)$, i.e.

$$
R P V_{i t}=\sqrt{\sum_{j=1}^{12} w_{i j t}\left(\pi_{i j t}-\pi_{i t}\right)^{2}}
$$

where $\pi_{i j t}=\Delta \ln P_{i j t}$ and $P_{i j t}$ is the price index of the $j$ th subcategory in country $i$ in period $t . w_{i j t}$ denotes the country-specific weight of the $j$ th subcategory in the aggregate index so that $P_{i t}=\sum_{j=1}^{12} w_{i j t} P_{i j t}$ gives the aggregate price level in country $i$ and the inflation rate $\pi_{i t}$ is $\Delta l n P_{i t}$. Note that the country-specific weights are not time invariant but are adjusted on a yearly basis by Eurostat. 
Figure 2: Distribution of national headline inflation rates in the euro area

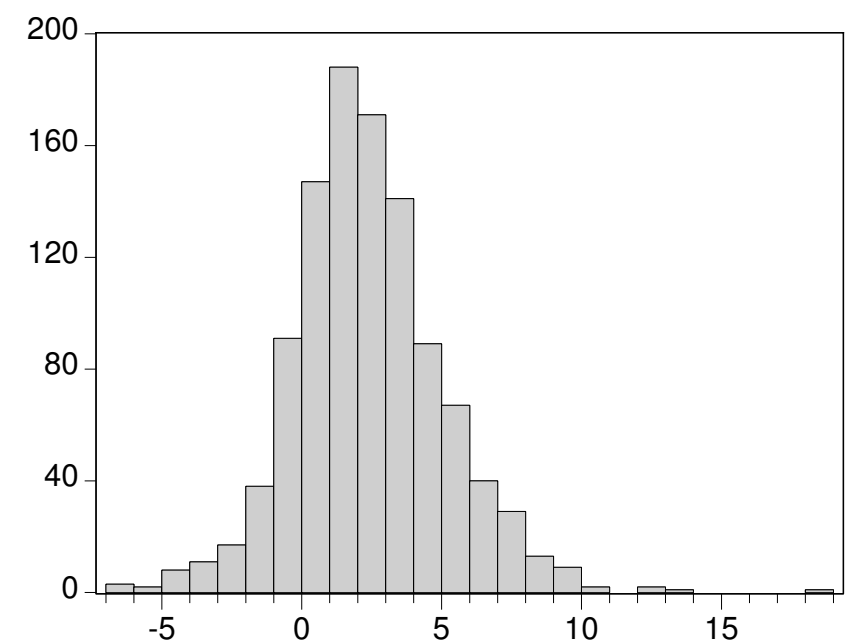

\begin{tabular}{|lr|}
\hline \multicolumn{2}{|l|}{ Annualized Inflation } \\
\multicolumn{2}{|l|}{ Sample 1995.02-2003.12 } \\
(Observations 1070) \\
Minimum & -6.30 \\
Maximum & 18.35 \\
Mean & 2.38 \\
Median & 2.19 \\
Lower Quartile & 0.68 \\
Upper Quartile & 3.88 \\
Std. Dev. & 2.69 \\
Skewness & 0.43 \\
Kurtosis & 4.81 \\
\hline
\end{tabular}

Notes: Annualized national inflation rates (percentage points, seasonally adjusted) confer to the harmonized index of consumer prices, 1995.02-2003.12. Source: Eurostat.

Figure 1 shows the behavior of the annualized inflation rate in the euro area. Accounting for the inflation differentials between the EMU member countries, Figure 1 also displays two generated time series consisting of the minimum and maximum of the countryspecific annualized inflation rates across the EMU countries. ${ }^{3}$ The inflation rate of the euro area is more closely related to the behavior of the country-specific minimum inflation. Since the mid-nineties, inflation in the euro area has been at a moderate level but there were also negative inflation rates as well as relatively high inflation in the euro area countries. As the histogram of annualized inflation rates in Figure 2 indicates, $25 \%$ of the observations are below an inflation rate of $0.68 \%$ p.a. and above an inflation rate of $3.88 \%$ p.a., respectively. More than half of the inflation observations exceed the $2 \%$ level.

The inflation-RPV relation might be distorted by supply shocks which jointly determine headline inflation and relative price variability. For example, if there is a positive supply shock in a product market then there is a fluctuation in that product price.

\footnotetext{
${ }^{3}$ The annualized inflation rates and RPV measures for the 10 countries under investigation are displayed in Figure 3 in the Appendix.
} 
This will lead to an increase in both average inflation and in the RPV measure. Consequently, there is correlation between headline inflation and the error term in the regression implying that the aggregate inflation can no longer be regarded as exogenous. A possible solution to this endogeneity bias is the application of core inflation as explanatory variable, see e.g. Jaramillo (1999) or Bomberger and Makinen (1993).

Our measure of core inflation is aggregate inflation without food and energy prices, i.e. prices that are particularly driven by supply side shocks. This inflation measure is also regularly monitored by the ECB, see e.g. ECB (2005). Core inflation for the ten countries is published by Eurostat and available from February 1996 onwards. The time series for annualized core inflation are displayed in Figure 4 in the Appendix. Apparently, inflation and core inflation show a concurrent pattern. In most periods, the differences between headline and core inflation seem not very dramatic. In particular, the coefficient of correlation between monthly aggregate inflation and core inflation over all countries is $0.63{ }^{4}$

Preannounced relative price changes increase RPV but are likely to be less distorting for the information content of prices. Therefore, we account for all ascertainable anticipated effects like e.g. the introduction of a tuition fee in Austria in October 2001. Additionally, we capture major institutional changes like e.g. the introduction of the Euro in January 1999 or the entrance of Greece to the European Monetary Union in January 2001 by including dummy variables in the following regressions.

Panel unit root tests for monthly headline inflation, core inflation, and RPV indicate that these time series have no individual or common unit root, see Table 5 in the Appendix for detailed results. Confirming the evidence provided by e.g. Lünnemann and Mathä (2004) or Hondroyiannis and Lazaretou (2004), inflation persistence in the euro area has declined in the end of the nineties.

\footnotetext{
${ }^{4}$ The histogram of annualized core inflation rates as well as the minimum and maximum core inflation rates are similar to the figures of headline inflation and are displayed in Figures 5 and 6 , respectively, in the Appendix.
} 
Table 1: The linear relation between inflation and RPV

\begin{tabular}{c|cc}
\multicolumn{3}{c}{$R P V_{i t}=\alpha_{i}+\beta\left|\pi_{i t}\right|+\varepsilon_{i t}$} \\
\hline \hline$\widehat{\beta}$ & headline inflation & core inflation \\
\hline \hline \multirow{2}{*}{ Exogeneity test (F-statistic) } & $0.46^{* *}$ & $0.59^{* *}$ \\
$\bar{R}^{2}$ & $(0.05)$ & $(0.05)$ \\
Observations & 8.01 & 1.01 \\
Countries & {$[0.00]$} & $0.32]$ \\
& 0.24 & 950 \\
& 1070 & 10 \\
\hline
\end{tabular}

Notes: ${ }^{* *}$ indicate significance at the $1 \%$ level. Standard errors are given in parentheses, pvalues in brackets. The exogeneity test is a test of exogeneity for a panel regression estimated via instrumental variables. The null hypothesis states that an ordinary least squares (OLS) estimator of the same equation would yield consistent estimates.

\subsection{Inflation and RPV: the basic relationship}

Following Parsley's (1996) and Debelle and Lamont's (1997) analysis of the inflationRPV link for US cities, let us begin with a simple least squares panel regression of RPV on the absolute value of aggregate inflation with country-specific fixed effects $\alpha_{i}:{ }^{5}$

$$
R P V_{i t}=\alpha_{i}+\beta\left|\pi_{i t}\right|+\varepsilon_{i t} .
$$

The results for the fixed-effects estimation (1) for the two alternative inflation measures are reported in Table 1. In both cases, inflation has a significant and positive impact on RPV.

However, the estimates based on headline inflation have to be interpreted with caution. In particular, the Davidson-MacKinnon exogeneity test rejects the null hypothesis of

\footnotetext{
${ }^{5}$ Parsley (1996) and Debelle and Lamont (1997) also include time dummies to control for shocks that hit all cities in a uniform manner. Since inclusion of time dummies does not alter our results qualitatively, we only present results refering to estimations without time dummies. The regressions of Equation (1) assume neither cross-section heteroskedasticity which allows for a different residual variance for each cross-section nor contemporaneous correlation between the cross-section residuals. If we allow for cross-section heteroskedasticity and contemporaneous correlation, the results do not change substantially.
} 
exogeneity of headline inflation at the $1 \%$ level. ${ }^{6}$ In contrast, the Davidson-McKinnon test shows that there is no endogeneity bias if we use the absolute value of core inflation. Accordingly, the core inflation rate is the appropriate inflation measure for the following empirical investigations.

\subsection{Expected inflation versus unexpected inflation}

The empirical results presented in the previous subsection showed that relative price variability in Europe increases in inflation. According to the simple linear specification (1), the impact of inflation on RPV does not depend on inflation expectations. However, a different role of expected and unexpected inflation is not only found empirically (Aarstol (1999), Nautz and Scharff (2005)) but also suggested by various theories explaining the inflation-RPV link.

Menu cost models by Sheshinski and Weiss (1977) or Rotemberg (1983) emphasize a positive relationship between RPV and expected inflation. If there are fixed cost of price changes and firm-specific shocks, staggered price setting will be generated and higher expected inflation will amplify the dispersion of prices. In contrast, only unexpected inflation has an impact on RPV in signal-extraction models introduced by Barro (1976) or Hercowitz (1981). In these models, individuals have difficulties distinguishing between relative and aggregate price changes. Since inflation uncertainty hampers the distinction between relevant idiosyncratic and irrelevant aggregate demand shocks, it becomes optimal for firms to adjust output less in response to all shocks. As a consequence of the implied misperceptions, prices have to move more in each market to equate quantity demanded with the less variable quantity supplied. If price elasticities of supply differ across firms, then RPV will respond to the magnitude of unexpected inflation.

\footnotetext{
${ }^{6}$ The Davidson-MacKinnon test computes a test of exogeneity for a fixed-effect regression estimated via instrumental variables, see Davidson and MacKinnon (1993). A rejection of the null hypothesis indicates that endogenous regressors' effects on the estimates are meaningful, and instrumental variables techniques are required.
} 
An obvious extension of the basic inflation-RPV relationship is, therefore, to allow for different coefficients on expected $\left(\pi_{i t}^{e}\right)$ and unexpected $\left(\pi_{i t}-\pi_{i t}^{e}\right)$ inflation:

$$
R P V_{i t}=\alpha_{i}+\beta_{1}\left|\pi_{i t}^{e}\right|+\beta_{2}\left|\pi_{i t}-\pi_{i t}^{e}\right|+\varepsilon_{i t},
$$

where $\alpha_{i}$ are again the fixed effects for each country. Typically, the empirical literature uses simple autoregressive time series representations to estimate inflation forecasts. Following e.g. Bomberger and Makinen (1993), Silver and Ioannidis (2001), Konieczny and Skrzypacz (2005), we estimate expected and unexpected inflation in Equation (2) using an $\mathrm{AR}(12)$ core inflation forecast for each country.

The first column of Table 2 shows the results for the fixed effects estimation of Equation (2). In line with the findings for Germany obtained by Nautz and Scharff (2005), the impact of unexpected inflation is much stronger in the euro area. An F-Test of the null hypothesis that the coefficients on expected and unexpected inflation are equal indicates rejection at the $1 \%$ level. Nautz and Scharff (2005) argue that the influence of expected inflation in Germany disappears because a credible monetary policy stabilized inflationary expectations on a low level. In fact, Konieczny and Skrzypacz (2005) establish a more pronounced effect of expected inflation during the transition of Poland from a planned to a market economy when inflation expectations were relatively high.

For the US, Aarstol (1999) finds that the effect of inflation on RPV is more pronounced when inflation is unexpectedly high, i.e. when unexpected inflation is positive. Following this approach, we regress RPV on expected as well as positive and negative unexpected inflation:

$$
R P V_{i t}=\alpha_{i}+\beta_{1}\left|\pi_{i t}^{e}\right|+\beta_{2}\left(\pi_{i t}-\pi_{i t}^{e}\right)^{+}+\beta_{3}\left|\left(\pi_{i t}-\pi_{i t}^{e}\right)^{-}\right|+\varepsilon_{i t},
$$

where $\left(\pi_{i t}-\pi_{i t}^{e}\right)^{+}=\left(\pi_{i t}-\pi_{i t}^{e}\right)$ if $\left(\pi_{i t}-\pi_{i t}^{e}\right) \geq 0$ and $\left(\pi_{i t}-\pi_{i t}^{e}\right)^{-}=\left(\pi_{i t}-\pi_{i t}^{e}\right)$ if $\left(\pi_{i t}-\pi_{i t}^{e}\right) \leq 0$ (zero otherwise). The fixed effects estimation of Equation (3) is reported in the second column of Table 2. The results indicate no rejection of the null hypothesis that the coefficients of positive and negative unexpected inflation are equal. Thus, there 
Table 2: The effects of expected and unexpected inflation on RPV

\begin{tabular}{|c|c|c|}
\hline & $\begin{aligned} R P V_{i t}= & \alpha_{i}+\beta_{1}\left|\pi_{i t}^{e}\right| \\
& +\beta_{2}\left|\pi_{i t}-\pi_{i t}^{e}\right|+\varepsilon_{i t}\end{aligned}$ & $\begin{aligned} R P V_{i t}= & \alpha_{i}+\beta_{1}\left|\pi_{i t}^{e}\right|+\beta_{2}\left(\pi_{i t}-\pi_{i t}^{e}\right)^{+} \\
& +\beta_{3}\left|\left(\pi_{i t}-\pi_{i t}^{e}\right)^{-}\right|+\varepsilon_{i t}\end{aligned}$ \\
\hline$\widehat{\beta}_{1}$ & $\begin{array}{l}0.26^{* *} \\
(0.09)\end{array}$ & $\begin{array}{l}0.27^{* *} \\
(0.09)\end{array}$ \\
\hline$\widehat{\beta}_{2}$ & $\begin{array}{l}1.13^{* *} \\
(0.07)\end{array}$ & $\begin{array}{l}1.06^{* *} \\
(0.09)\end{array}$ \\
\hline$\widehat{\beta}_{3}$ & & $\begin{array}{l}1.20^{* *} \\
(0.09)\end{array}$ \\
\hline$F\left(\widehat{\beta}_{1}=\widehat{\beta}_{2}\right)$ & $\begin{array}{l}50.88 \\
{[0.00]}\end{array}$ & \\
\hline$F\left(\widehat{\beta}_{2}=\widehat{\beta}_{3}\right)$ & & $\begin{array}{l}1.85 \\
{[0.17]}\end{array}$ \\
\hline $\bar{R}^{2}$ & 0.34 & 0.34 \\
\hline Obs. & 830 & 830 \\
\hline Countries & 10 & 10 \\
\hline
\end{tabular}

Notes: Expected and unexpected inflation are based on a $\operatorname{AR}(12)$ forecast of core inflation. ** indicate significance at the $1 \%$ level. Standard errors are given in parentheses, p-values in brackets. $F\left(\widehat{\beta}_{i}=\widehat{\beta}_{j}\right)$ indicates the F-statistic testing $H_{0}: \widehat{\beta}_{i}=\widehat{\beta}_{j}$.

is no evidence for an asymmetric impact of unexpected inflation on RPV in Europe. As a consequence, Equation (2) shall be regarded as a starting point for a deeper analysis of the inflation-RPV relationship.

\section{The non-linear relation between inflation and RPV}

The previous section established a linear relationship between inflation and RPV in the European Monetary Union assuming that the significance and strength of the impact of expected and unexpected inflation do not depend on the level of inflation. This assumption is, however, debatable.

On the one hand, a linear influence of inflation on RPV and, thus on welfare, seems to be at odds with the non-linear behavior and strategies of many central banks. The $\mathrm{ECB}$, for example, defines price stability as an inflation rate "below but close to $2 \%$ ". As a consequence, the central bank's reaction to an increase in the inflation rate from, 
say, $1 \%$ to $1.5 \%$, may be qualitatively very different from an increase from $2 \%$ to $2.5 \%$. Similar non-linear policy responses may be observed for inflation reductions if inflation is already close to zero. This suggests that central banks' perception of the real effects of inflation assume certain threshold values of inflation.

On the other hand, the (non-)linearity of the impact of inflation on RPV is also discussed in the empirical literature. Since the early findings of Parks (1978) it has been repeatedly suspected that the empirical evidence in favor of a positive link between US inflation and RPV might be only due to a few high inflation periods, see Jaramillo (1999). ${ }^{7}$ Caglayan and Filiztekin (2003) were the first who explicitly allowed the coefficient of inflation to vary with the level of inflation. They use panel data of Turkish provinces and find that the impact of inflation on RPV depends on the inflation regime. The following analysis of the non-linear impact of inflation on RPV in Europe advances in several dimensions on Caglayan and Filiztekin (2003).

First, Caglayan and Filiztekin (2003) divided the sample ad hoc in a high and a low inflation period. For Turkey, this pragmatic approach is appropriate because Turkey has been through two distinct inflationary periods after 1948. In fact, there is an obvious structural break in the behavior and the average level of Turkish inflation before and after 1976. However, since the mid-nineties, the identification of different inflation periods is not obvious for most European countries, compare Fig. 4. Second, Caglayan and Filiztekin (2003) divide the observation period in a low and a high inflation episode uniformly for all cross-sectional units. As a consequence, all cross-section units are in the same inflation regime. For European countries, this assumption is not appropriate. In fact, there have been substantial inflation differentials between the member countries of the EMU, i.e. different European countries are probably in different inflation regimes. Finally, with a view to the obvious break in the Turkish inflation record Caglayan and Filiztekin (2003) determine the number of thresholds and the threshold value itself

\footnotetext{
${ }^{7}$ Note, however, that Nautz and Scharff (2005) found evidence for an impact of (unexpected) inflation on RPV even in Germany, the textbook example of a low-inflation country.
} 
exogenously. Again, this research strategy should not be applied to European data, since the existence and identification of distinct inflationary episodes is far from obvious for the relatively low inflation rates observed in the European Monetary Union.

A natural candidate to solve many problems of the ad hoc approach applied in Caglayan and Filiztekin (2003) is the panel threshold regression model introduced by Hansen $(1999,2000)$. In that model, different countries are not only allowed to be in different inflation regimes. Hansen $(1999,2000)$ also provides tests for the number of thresholds and estimates the threshold values, i.e. the critical inflation levels where the impact of inflation on RPV changes. Therefore, Hansen's panel threshold model is an obvious first step to analyze potential non-linearities in the impact of inflation on RPV in Europe. In the next section, the panel threshold model is introduced. Following Hansen (1999, 2000), we will briefly review how to estimate and evaluate single and multiple panel threshold models.

\section{The Panel-Threshold-Model}

\subsection{The single threshold model}

\subsubsection{Estimation of a single threshold}

This section introduces the panel threshold model by Hansen $(1999,2000)$. Starting with the single threshold case, the equation for a balanced panel with threshold effects is given as:

$$
y_{i t}=\alpha_{i}+\beta_{1}^{\prime} x_{i t} I\left(q_{i t} \leq \gamma\right)+\beta_{2}^{\prime} x_{i t} I\left(q_{i t}>\gamma\right)+\varepsilon_{i t},
$$

where $I(\cdot)$ is an indicator function. The error term $\varepsilon_{i t}$ is independent and identically distributed with zero mean and finite variance $\sigma^{2}$. The subscript $i$ stands for the crosssections with $1 \leq i \leq N$ and $t$ indexes time $(1 \leq t \leq T)$. The dependent variable $y_{i t}$ and the threshold variable $q_{i t}$ are scalar, the regressor $x_{i t}$ is a $k$-dimensional vector of exogenous variables. $x_{i t}$ and $y_{i t}$ are assumed to be stationary variables. $x_{i t}$ may contain 
variables with slope coefficients constrained to be the same in the two regimes which have no effect on the following distribution theory. If the threshold variable $q_{i t}$ is below or above a certain value of $q_{i t}$, namely $\gamma$, then the regressor $x_{i t}$ has a different impact on $y_{i t}$ represented by coefficients $\beta_{1} \neq \beta_{2}$. In many applications, the threshold variable $q_{i t}$ may be an element of $x_{i t}$ but this is not necessarily the case. In our application $y_{i t}$ is RPV and a natural choice of $q_{i t}$ is a measure of inflation. $x_{i t}$ contains expected and unexpected inflation.

Hansen $(1999,2000)$ chooses a fixed effects approach to estimate Equation (4). After removing the individual specific means $\alpha_{i}$, the slope coefficient $\beta$ can be estimated (for given $\gamma$ ) by ordinary least squares (OLS). Restating Equation (4) as:

$$
y_{i t}=\alpha_{i}+\beta^{\prime} x_{i t}(\gamma)+\varepsilon_{i t},
$$

where $x_{i t}(\gamma)=\left(\begin{array}{l}x_{i t} I\left(q_{i t} \leq \gamma\right) \\ x_{i t} I\left(q_{i t}>\gamma\right)\end{array}\right)$ and $\beta=\left(\beta_{1}^{\prime} \beta_{2}^{\prime}\right)^{\prime}$, the OLS estimator of $\beta$ is obtained by

$$
\hat{\beta}(\gamma)=\left(X^{*}(\gamma)^{\prime} X^{*}(\gamma)\right)^{-1} X^{*}(\gamma)^{\prime} Y^{*}
$$

$X^{*}$ and $Y^{*}$ denote the stacked data over all individuals after removing the individual specific means. The vector of regression residuals is $\hat{\varepsilon}^{*}(\gamma)=Y^{*}-X^{*}(\gamma) \hat{\beta}(\gamma)$ and the sum of squared errors can be written as

$$
S_{1}(\gamma)=\hat{\varepsilon}^{*}(\gamma)^{\prime} \hat{\varepsilon}^{*}(\gamma)=Y^{*^{\prime}}\left(I-X^{*}(\gamma)^{\prime}\left(X^{*}(\gamma)^{\prime} X^{*}(\gamma)\right)^{-1} X^{*}(\gamma)^{\prime}\right) Y^{*}
$$

In a second step, Hansen (2000) suggests the estimation of the threshold $\gamma$ by least squares, implying

$$
\hat{\gamma}=\underset{\gamma}{\operatorname{argmin}} S_{1}(\gamma)
$$

The resulting estimate for the slope coefficient is obtained by $\hat{\beta}=\hat{\beta}(\hat{\gamma})$. The residual vector is $\hat{\varepsilon}^{*}=\hat{\varepsilon}^{*}(\hat{\gamma})$ and the residual variance is defined as

$$
\hat{\sigma}^{2}=\frac{1}{N(T-1)} \hat{\varepsilon}^{*^{\prime}} \hat{\varepsilon}^{*}=\frac{1}{N(T-1)} S_{1}(\hat{\gamma}) .
$$




\subsubsection{Testing for a threshold}

Having estimated the single threshold $\hat{\gamma}$, it is important to check whether the threshold is in fact statistically significant. Obviously, the null hypothesis "no threshold effect in Equation (4)" is equivalent to

$$
H_{0}: \quad \beta_{1}=\beta_{2}
$$

Note that standard tests have non-standard distributions, since under $H_{0}$ the threshold is not identified. For fixed-effects equations, Hansen (1996) therefore suggests a bootstrap method to simulate the asymptotic distribution of the likelihood ratio test. Under the null hypothesis of no threshold, the model is

$$
y_{i t}=\alpha_{i}+\beta_{1}^{\prime} x_{i t}+\varepsilon_{i t}
$$

After the fixed effects transformation, the equation can be written as

$$
y_{i t}^{*}=\beta_{1}^{\prime} x_{i t}^{*}+\varepsilon_{i t}^{*}
$$

The OLS estimator of $\beta_{1}$ is $\tilde{\beta}_{1}$, the residuals are $\tilde{\varepsilon}_{i t}^{*}$ and the sum of squared errors is $S_{0}=\tilde{\varepsilon}_{i t}^{*} \tilde{\varepsilon}_{i t}^{*}$. Then, the likelihood ratio test of $H_{0}$ is based on the test statistic

$$
F_{1}=\frac{S_{0}-S_{1}(\hat{\gamma})}{\hat{\sigma}^{2}}
$$

where $\hat{\sigma}^{2}$ is the residual variance defined in (9). Hansen (1996) shows that a bootstrap procedure achieves the first-order asymptotic distribution, so p-values constructed from the bootstrap are asymptotically valid.

In the following, we adopt the bootstrap method by Hansen (1999) but modify the procedure. Hansen (1999) has a large number of cross sections $(N \rightarrow \infty)$ but only a few time periods. In contrast, the number of countries in our sample is ten but $T$ is large. ${ }^{8}$

\footnotetext{
${ }^{8}$ Hansen (1999) groups the regression residuals by individual $\hat{\varepsilon}_{i}^{*}=\left\{\hat{\varepsilon}_{i 1}^{*}, \hat{\varepsilon}_{i 2}^{*}, \ldots, \hat{\varepsilon}_{i T}^{*}\right\}$ and takes the sample $\left\{\hat{\varepsilon}_{1}^{*}, \hat{\varepsilon}_{2}^{*}, \ldots, \hat{\varepsilon}_{N}^{*}\right\}$ with size $N$ as the empirical distribution. Since $N$ is limited but $T$ is large in our empirical analysis, we treat the sample $\left\{\hat{\varepsilon}_{11}^{*}, \ldots, \hat{\varepsilon}_{1 T}^{*}, \ldots, \hat{\varepsilon}_{i 1}^{*}, \ldots, \hat{\varepsilon}_{i T}^{*}, \ldots, \hat{\varepsilon}_{N 1}^{*}, \ldots, \hat{\varepsilon}_{N T}^{*}\right\}$ as the
} 


\subsubsection{Confidence intervals for threshold estimate and slope coefficients}

In case of a threshold effect, i.e. $\beta_{1} \neq \beta_{2}$, the estimate $\hat{\gamma}$ is consistent for the true value of $\gamma$, say $\gamma_{0}$. Since the asymptotic distribution of the threshold estimate $\hat{\gamma}$ is highly non-standard, Hansen (2000) uses the likelihood ratio statistic for tests on $\gamma$ to form confidence intervals for $\gamma$. The null hypothesis is $H_{0}: \gamma=\gamma_{0}$ and the likelihood ratio statistic is given by

$$
L R_{1}(\gamma)=\frac{S_{1}(\gamma)-S_{1}(\hat{\gamma})}{\hat{\sigma}^{2}}
$$

The null hypothesis is rejected for large values of $L R_{1}\left(\gamma_{0}\right)$. Hansen (2000) shows that there is an asymptotic distribution for $T \rightarrow \infty$ or $N \rightarrow \infty$ to form valid asymptotic confidence intervals for $\gamma \cdot{ }^{9}$ He demonstrates that the distribution function has the inverse $c(\alpha)=-2 \ln (1-\sqrt{1-\alpha})$ from which it is easy to calculate critical values, e.g. the $5 \%$ critical value is 7.35 and the $1 \%$ critical value is 10.59 . The test rejects the hypothesis $H_{0}: \gamma=\gamma_{0}$ at the asymptotic level $\alpha$ if $L R_{1}\left(\gamma_{0}\right)$ exceeds $c(\alpha)$. The asymptotic $(1-\alpha)$ confidence interval for $\gamma$ is the set of values of $\gamma$ such that $L R_{1}(\gamma) \leq$ $c(\alpha)$. Note that this confidence interval construction can produce highly asymmetric confidence intervals for $\gamma$.

The asymptotic distribution of the slope coefficients $\hat{\beta}$ is more straightforward, although the estimator $\hat{\beta}=\hat{\beta}(\hat{\gamma})$ depends on the threshold estimate $\hat{\gamma}$. Hansen (2000) shows that inference on $\beta$ can proceed as if the threshold estimate $\hat{\gamma}$ were the true value. Therefore,

empirical distribution to be used for bootstrapping. For the bootstrap procedure, the variable $x_{i t}$ and the threshold variable $q_{i t}$ are given, i.e. their values are fixed in repeated bootstrap samples. We take with replacement a sample of size $N T$ from the empirical distribution and create a bootstrap sample under the null hypothesis of no threshold. This bootstrap sample is used to estimate the model under $H_{0}$ and $H_{1}$ and to calculate the bootstrap value of the likelihood ratio statistic $F_{1}$ (12). This procedure is frequently repeated -1000 bootstrap replications in our application - and the bootstrap estimate of the asymptotic p-value for $F_{1}$ under $H_{0}$ is the percentage of draws for which the simulated likelihod ratio statistic exceeds the actual statistic. The null hypothesis of no threshold effect is rejected if the p-value is smaller than the desired significance level.

${ }^{9}$ Hansen (1999) mentioned that the asymptotic approximation of the distribution of the likelihood ratio statistic is likely to hold better for cases where $\beta_{2}-\beta_{1}$ is small than for cases where it is large. However, if the threshold effect is large the threshold will be quite precisely estimated. 
$\hat{\beta}$ is asymptotically normal with covariance matrix $V$ estimated by

$$
\widehat{V}=\left(\sum_{i=1}^{N} \sum_{t=1}^{T} x_{i t}^{*}(\hat{\gamma}) x_{i t}^{*}(\hat{\gamma})^{\prime}\right)^{-1} \hat{\sigma}^{2} .
$$

\subsection{Multiple thresholds}

\subsubsection{Estimating multiple thresholds}

In many applications, there may be more than only one threshold. For example, there are two thresholds accounting for non-linearities in the relationship between inflation and growth in Europe, see Cuaresma and Silgoner (2004). Fortunately, the testing and estimation procedure by Hansen $(1999,2000)$ allows for the possibility of multiple thresholds. In the following, we illustrate the methods for the double threshold model since these methods extend in straightforward way to higher order threshold models. The double threshold model has the form

$$
y_{i t}=\alpha_{i}+\beta_{1}^{\prime} x_{i t} I\left(q_{i t} \leq \gamma_{1}\right)+\beta_{2}^{\prime} x_{i t} I\left(\gamma_{1}<q_{i t} \leq \gamma_{2}\right)+\beta_{3}^{\prime} x_{i t} I\left(\gamma_{2}<q_{i t}\right)+\varepsilon_{i t}
$$

with $\gamma_{1}<\gamma_{2}$. Equation (14) can be estimated by OLS, since for given thresholds (14) is linear in slopes. The sum of squared residuals $S\left(\gamma_{1}, \gamma_{2}\right)$ can be calculated as in the single threshold model and the joint least squares estimates of $\left(\gamma_{1}, \gamma_{2}\right)$ are the values which jointly minimize $S\left(\gamma_{1}, \gamma_{2}\right)$. Since a grid search over $\left(\gamma_{1}, \gamma_{2}\right)$ requires approximately $(N T)^{2}$ regressions, it is important that - as Hansen (1999) demonstrates - sequential estimation is consistent. ${ }^{10}$ In the first stage, $\hat{\gamma}_{1}$ is the threshold estimate which minimizes $S_{1}(\gamma)$ defined in (7). Given the first-stage estimate $\hat{\gamma}_{1}$, the criterion for the second stage is in Hansen's (1999) notation given by

$$
S_{2}^{r}\left(\gamma_{2}\right)=\left\{\begin{array}{ll}
S\left(\hat{\gamma}_{1}, \gamma_{2}\right) & \text { if } \hat{\gamma}_{1}<\gamma_{2} \\
S\left(\gamma_{2}, \hat{\gamma}_{1}\right) & \text { if } \gamma_{2}<\hat{\gamma}_{1}
\end{array} .\right.
$$

The second-stage threshold estimate can then be written as

$$
\hat{\gamma}_{2}^{r}=\underset{\gamma_{2}}{\operatorname{argmin}} S_{2}^{r}\left(\gamma_{2}\right)
$$

\footnotetext{
10 This result was found in the multiple changepoint model literature, see e.g. Bai (1997) or Bai and Perron (1998).
} 
As Bai (1997) has shown, the estimator for $\gamma_{2}$ is asymptotically efficient. However, since $\hat{\gamma}_{1}$ was obtained from a sum of squared residuals function which neglects the second threshold, $\hat{\gamma}_{1}$ is not efficient. Bai (1997) suggests a third-stage estimation to get an asymptotically efficient estimator for $\gamma_{1}$. Holding the second-stage estimate $\hat{\gamma}_{2}^{r}$ fix, the third-stage criterion is

$$
S_{1}^{r}\left(\gamma_{1}\right)=\left\{\begin{array}{ll}
S\left(\gamma_{1}, \hat{\gamma}_{2}^{r}\right) & \text { if } \gamma_{1}<\hat{\gamma}_{2}^{r} \\
S\left(\hat{\gamma}_{2}^{r}, \gamma_{1}\right) & \text { if } \hat{\gamma}_{2}^{r}<\gamma_{1}
\end{array} .\right.
$$

Then, the estimate for $\gamma_{1}$ is obtained by

$$
\hat{\gamma}_{1}^{r}=\underset{\gamma_{1}}{\operatorname{argmin}} S_{1}^{r}\left(\gamma_{1}\right)
$$

\subsubsection{Testing for the number of thresholds}

Let us now determine the number of thresholds in a multiple threshold model. Again, the procedure is illustrated in the double threshold model, since the generalization to more than two thresholds is straightforward. In the single threshold model $F_{1}$ in (12) is obtained as the test statistic for a test of no thresholds against one threshold. If $F_{1}$ rejects the null of no threshold, we need a further test to discriminate between one and two thresholds. The minimized sum of squared errors from the second stage threshold estimate $\hat{\gamma}_{2}^{r}$ is $S_{2}^{r}\left(\hat{\gamma}_{2}^{r}\right)$ with the variance estimate $\hat{\sigma}^{2}=S_{2}^{r}\left(\hat{\gamma}_{2}^{r}\right) / N(T-1)$. Thus, the likelihood ratio statistic for a test of one versus two thresholds is given by

$$
F_{2}=\frac{S_{1}\left(\hat{\gamma}_{1}\right)-S_{2}^{r}\left(\hat{\gamma}_{2}^{r}\right)}{\hat{\sigma}^{2}} .
$$

The null of one threshold is rejected if $F_{2}$ is large. The bootstrap procedure to approximate the asymptotic p-value for the likelihood ratio test works as for the singlethreshold case. The threshold variable $q_{i t}$ and the regressors $x_{i t}$ are fixed in repeated bootstrap samples. The bootstrap errors will be drawn from the residuals calculated under the alternative hypothesis, i.e. from the residuals from least squares regression of Equation (14). Specifically, we draw (with replacement) error samples from the empirical distribution, namely $\varepsilon_{i t}^{\sharp}$. Now we generate the dependent variable $y_{i t}^{\sharp}$ under the 
null hypothesis of one threshold using the equation

$$
y_{i t}^{\sharp}=\hat{\beta}_{1}^{\prime} x_{i t} I\left(q_{i t} \leq \hat{\gamma}\right)+\hat{\beta}_{2}^{\prime} x_{i t} I\left(q_{i t}>\hat{\gamma}\right)+\varepsilon_{i t}^{\sharp} .
$$

Equation (20) depends on the least squares estimates from the single threshold model $\hat{\beta}_{1}, \hat{\beta}_{2}$, and $\hat{\gamma}$. The test statistic $F_{2}$ can be calculated and repeating this procedure a large number of times will provide the bootstrap p-value. Note that in the generalized case the sequential testing sequence stops if e.g. the null of a maximum number of $(K-1)$ thresholds is rejected but the null of at most $K$ thresholds is not.

\subsubsection{Confidence Intervals}

Following Bai (1997), the threshold estimators $\hat{\gamma}_{1}^{r}$ and $\hat{\gamma}_{2}^{r}$ have the same asymptotic distributions as the threshold estimate in the single threshold model. Consequently, the confidence intervals for the two threshold parameters are constructed in the same way as in the single threshold case. We calculate

$$
\operatorname{LR}_{2}^{r}(\gamma)=\frac{S_{2}^{r}(\gamma)-S_{2}^{r}\left(\hat{\gamma}_{2}^{r}\right)}{\hat{\sigma}^{2}}
$$

and

$$
L R_{1}^{r}(\gamma)=\frac{S_{1}^{r}(\gamma)-S_{1}^{r}\left(\hat{\gamma}_{1}^{r}\right)}{\hat{\sigma}^{2}}
$$

where $S_{2}^{r}(\gamma)$ and $S_{1}^{r}(\gamma)$ are defined in (15) and (17), respectively. Then, the asymptotic $(1-\alpha)$ confidence regions for the threshold estimates are the set of values of $\gamma$ with $L R_{2}^{r}(\gamma) \leq c(\alpha)$ and $L R_{1}^{r}(\gamma) \leq c(\alpha)$.

\section{Inflation thresholds and RPV: Empirical results for the euro area}

\subsection{Model specification}

In the following we apply the panel-threshold model reviewed in the previous section to the analysis of the relationship between RPV and inflation in the euro area. According 
to the evidence found in Section 2, we use the linear specification (2) that allows for a different impact of expected $\left(\pi_{i t}^{e}\right)$ and unexpected $\left(\pi_{i t}-\pi_{i t}^{e}\right)$ core inflation on RPV as the starting point of our analysis. Thus, using the notation of the threshold model introduced in Section 4, we have $y_{i t}=R P V_{i t}$ and $x_{i t}=\left(\left|\pi_{i t}^{e}\right|,\left|\pi_{i t}-\pi_{i t}^{e}\right|\right)$.

In the next step, the threshold variable $q$ has to be determined. Section 2 provided clear evidence that core inflation is the relevant measure of inflation for RPV. Therefore, core inflation as threshold variable seems to be the most natural choice. In the following we will therefore concentrate on the results obtained for $q_{i t}=\pi_{i t}$. Yet, it is worth emphasizing that our major results are very robust with respect to alternative threshold variables like headline inflation or expected core inflation, see Tables 6 and 7 in the Appendix for detailed results. ${ }^{11}$

Finally, we have to determine whether expected and/or unexpected inflation may have a non-linear-threshold impact on RPV. Table 9 in the Appendix shows that the relation between unexpected inflation and RPV is linear. In the following, we therefore focus on the more interesting results we obtained for the non-linear influence of expected inflation on RPV. To summarize the above specification issues and to establish some notation, the specification of the threshold model employed in the following analysis is as follows:

$$
R P V_{i t}=\alpha_{i}+\sum_{k=0}^{K} \beta_{k+1}\left|\pi_{i t}^{e}\right| I\left(\gamma_{k}<\pi_{i t} \leq \gamma_{k+1}\right)+\delta\left|\pi_{i t}-\pi_{i t}^{e}\right|+\varepsilon_{i t},
$$

where $\gamma_{0}=-\infty, \gamma_{K+1}=\infty, K$ is the number of thresholds and, thus, $(K+1)$ the number of inflation regimes.

${ }^{11}$ If we use unexpected core inflation as threshold variable to determine different regimes for the effect of expected core inflation on RPV, the test for threshold effects arrives at the conclusion that there is no threshold (Table 8). The same result of no threshold effect is obtained when we allow the coefficient on unexpected core inflation to switch between regimes, see Table 9 in the Appendix. 
Table 3: Test procedure establishing the number of thresholds

\begin{tabular}{|c|c|}
\hline \multicolumn{2}{|l|}{$H_{0}:$ no threshold $(K=0)$} \\
\hline$F_{1}$ & 34.82 \\
\hline p-value & 0.00 \\
\hline$(10 \%, 5 \%, 1 \%$ critical values $)$ & $(8.12,9.85,15.07)$ \\
\hline \multicolumn{2}{|l|}{$H_{0}$ : at most one threshold $(K=1)$} \\
\hline$F_{2}$ & 13.94 \\
\hline p-value & 0.01 \\
\hline (10\%, $5 \%, 1 \%$ critical values $)$ & $(7.88,9.42,13.19)$ \\
\hline \multicolumn{2}{|l|}{$H_{0}$ : at most two thresholds $(K=2)$} \\
\hline$F_{3}$ & 3.34 \\
\hline p-value & 0.59 \\
\hline$(10 \%, 5 \%, 1 \%$ critical values $)$ & $(6.95,8.28,11.68)$ \\
\hline
\end{tabular}

\subsection{The number of inflation thresholds}

In order to determine the number of thresholds, the distinct values of the threshold variable core inflation are sorted. To ensure a minimum number of observations in each threshold regime, we restrict the search to values of monthly core inflation such that not less than $5 \%$ of the observations, i.e. at least 41 observations, lie in each regime, see e.g. Hansen (1999) or Cuaresma and Silgoner (2004). The remaining values of monthly core inflation (beginning with -0.1149 and ending with 0.5112 ) constitute the values of $\gamma$ which can be searched for $\hat{\gamma}$. As described in Section 4, Equation (21) is estimated by least squares and the sum of squared residuals (7) is calculated for each value of core inflation. The value that minimizes $(7)$ yields the estimate $\hat{\gamma} \cdot{ }^{12}$

12 The GAUSS program underlying this analysis is based on the GAUSS code by Bruce Hansen which is available from his homepage (http://www.ssc.wisc.edu/ bhansen/). 
Table 4: A double threshold model for the inflation-RPV link

\begin{tabular}{lr}
$R P V_{i t}=\alpha_{i}+\beta_{1}\left|\pi_{i t}^{e}\right| I\left(\pi_{i t} \leq \gamma_{1}\right)+\beta_{2}\left|\pi_{i t}^{e}\right| I\left(\gamma_{1}<\pi_{i t} \leq \gamma_{2}\right)+\beta_{3}\left|\pi_{i t}^{e}\right| I\left(\gamma_{2}<\pi_{i t}\right)+\delta\left|\pi_{i t}-\pi_{i t}^{e}\right|+\varepsilon_{i t}$ \\
\hline \hline Threshold estimates & \\
$\widehat{\gamma}_{1}$ & -0.1149 \\
$95 \%$ confidence interval & 0.4948 \\
$\widehat{\gamma}_{2}$ & {$[0.2401,0.5112]$} \\
$95 \%$ confidence interval & \\
\hline Regression estimates & \\
$\widehat{\beta}_{1}$ & $1.38^{* *}$ \\
$\widehat{\beta}_{2}$ & $(0.20)$ \\
$\widehat{\beta}_{3}$ & 0.05 \\
$\widehat{\delta}$ & $(0.10)$ \\
SSR & $0.50^{* *}$ \\
Observations in regime 1 & $(0.12)$ \\
Observations in regime 2 & $0.866^{* *}$ \\
Observations in regime 3 & $(0.08)$ \\
\hline
\end{tabular}

Notes: The threshold variable $\pi_{i t}$ is monthly core inflation. Standard errors are given in parentheses, p-values in brackets. ${ }^{* *}$ indicate significance at the $1 \%$ level.

The test statistics $F_{1}, F_{2}$ (see (12) and (19)), and $F_{3}$ together with their asymptotic bootstrap p-values are shown in Table 3 . According to the p-value associated to $F_{1}$, the null of no threshold effects can be rejected at the $1 \%$ level. The test statistic for a double threshold $F_{2}$ is also highly significant with a bootstrap p-value of 0.01 . However, the test statistic for a third threshold $\left(F_{3}\right)$ is far from being statistically significant. Therefore, the sequential test procedure implies two thresholds and, thus, three inflation regimes in the inflation-RPV relation for the euro area. 


\subsection{Estimating the inflation thresholds and the slope coefficients}

The estimated thresholds and the $95 \%$ confidence intervals are reported in the upper part of Table 4. The point estimates of the two thresholds for monthly core inflation are -0.1149 and 0.4948 . Note that -0.1149 for the threshold $\gamma_{1}$ is the smallest feasible threshold value having restricted the search for thresholds to values of $\gamma$ such that $5 \%$ of the observations lie in each regime. Therefore, the regime $\pi_{i t} \leq \hat{\gamma}_{1}$ contains exactly 41 observations and the lower bound of the $95 \%$ confidence interval is the threshold value itself. By contrast, the second threshold lies strictly within the confidence interval. The upper bound for the second threshold confidence interval is the last value of monthly core inflation being available for searching on $\hat{\gamma}{ }^{13}$

The different estimates $\left(\hat{\beta}_{1}, \hat{\beta}_{2}, \hat{\beta}_{3}\right)$ for the marginal impact of expected inflation in the three inflation regimes can be found in the lower part of Table 4. The coefficient of unexpected core inflation $(\hat{\delta})$ - the variable not switching between the regimes on RPV is positive and highly significant. In contrast, the significant linear relation between expected inflation and RPV presented in Section 2 is attributed to the positive impact of expected inflation if inflation is either very high or very low. Specifically, the expected inflation coefficients on the regimes 'very low inflation' and 'very high inflation' are highly significant while the coefficient on the intermediate regime $\left(\hat{\beta}_{2}\right)$ is not significantly different from zero. RPV reacts positively $\left(\hat{\beta}_{3}=0.5\right)$ to expected inflation if monthly core inflation exceeds $0.4948 \%$, i.e. if annualized core inflation is higher than $5.94 \%$. As the $95 \%$ confidence interval for monthly inflation indicates, the estimated value of this upper inflation threshold exceeds $2.88 \%$ p.a. Expected inflation has the strongest marginal impact on $\operatorname{RPV}\left(\hat{\beta}_{1}=1.38\right)$ if core inflation is lower than $-0.1149 \%$, i.e. $-1.38 \%$ p.a. ${ }^{14}$ A linear specification underestimates the role of expected

\footnotetext{
${ }^{13}$ If we allow for a minimum number of observations lying in each regime of only $2.5 \%$ or $1 \%$, the estimated lower threshold decreases and the large threshold increases. Since the estimated coefficients of expected inflation increase slightly with the absolute value of the thresholds, it seems that RPV reacts non-linear to inflation even within the regimes. This suggests that a smooth transition model might provide an alternative specification of the non-linear relation between inflation and RPV.

${ }^{14}$ Note that threshold $\hat{\gamma}_{1}$ is indeed the first threshold determined by the sequential test procedure.
} 
inflation for RPV in case of very high and very low inflation levels.

It is worth emphasizing that our results are robust with respect to the choice of the threshold variable. For example, as Tables 6 and 7 in the Appendix show, there are also two thresholds if the threshold variable is expected core inflation or headline inflation. In all these variants of the threshold model, the general conclusion remains: there is only a significant impact of expected inflation on RPV if inflation is either very low or very high supporting price stability as an outcome of optimal monetary policy.

\section{Conclusion}

The effects of inflation on the welfare of an economy are manifold. In particular, according to the new Keynesian macroeconomic literature price dispersion is responsible for real effects of inflation. Inflation increases relative price variability (RPV), distorts the information content of nominal prices and, thereby, impedes an efficient allocation of resources. This paper examines the empirical relationship between inflation and RPV in the euro area focusing on threshold effects of inflation. Specifically, we employ the panel threshold model proposed by Hansen (1999, 2000) since it allows to estimate the number of thresholds as well as the threshold values itself.

The results for the euro area reveal that the impact of expected inflation on RPV is hump-shaped. Expected inflation increases RPV if core inflation is either very low $(<-1.38 \%$ p.a. $)$ or very high ( $>5.94 \%$ p.a.). Between these two thresholds expected inflation has no real effects on the economy via its impact on RPV. Therefore, threshold effects of inflation provide a further rational for the announcement of critical levels of inflation and inflation target zones.

A similar threshold effect of inflation is also found in the inflation-growth literature,

Recall that in a double threshold model the lower threshold is not necessarily the first estimated threshold. This confirms the importance of the pronounced low-inflation-effect. In particular, there is only evidence for a single low inflation threshold if each regime has to contain at least $10 \%$ of all observations. 
see e.g. Cuaresma and Silgoner (2004). They find a hump-shaped impact of inflation on long-term growth in Europe, i.e. the relationship between inflation and growth is significant for low inflation rates, insignificant thereafter and again significant for highinflation levels. However, Cuaresma and Silgoner (2004) estimate an upper threshold of inflation of around $16 \%$ p.a. which seems to be of limited relevance for current monetary policy in industrial countries. In contrast, the upper threshold level in the inflationRPV relationship ranges between $3 \%$ and $6 \%$ p.a. confirming that price stability should be the outcome of optimal monetary policy.

Of course, threshold models may only provide a crude approximation of a very complex non-linear relation. Further steps in the empirical analysis of the non-linear impact of inflation on RPV might include the application of smooth transition models which have already been introduced by Tsionas and Christopoulos (2003) into the empirical inflation-growth literature.

\section{References}

Aarstol, M. (1999). Inflation, Inflation Uncertainty, and Relative Price Variability, Southern Economic Journal 66(2): 414-423.

Bai, J. (1997). Estimating multiple breaks one at a time, Econometric Theory 13: 315352.

Bai, J. and Perron, P. (1998). Estimating and Testing Linear Models with Multiple Structural Changes, Econometrica 66: 47-78.

Barro, R. J. (1976). Rational Expectations and the Role of Monetary Policy, Journal of Monetary Economics 2(1): 1-32.

Bomberger, W. A. and Makinen, G. E. (1993). Inflation and Relative Price Variability: Parks' Study Reexamined, Journal of Money, Credit, and Banking 25(4): 854-861. 
Breitung, J. (2000). The local power of some unit root tests for panel data, in B. Baltagi (ed.), Advances in Econometrics, Vol. 15: Nonstationary Panels, Panel Cointegration, and Dynamic Panels, JAI Press, Amsterdam, pp. 161-178.

Bruno, M. and Easterly, W. (1998). Inflation Crises and Long-Run Growth, Journal of Monetary Economics 41: 3-26.

Caglayan, M. and Filiztekin, A. (2003). Nonlinear Impact of Inflation on Relative Price Variability, Economics Letters 79: 213-218.

Chang, E. C. and Cheng, J. W. (2002). Inflation and Relative Price Variability: A Revisit, Applied Economics Letters 9: 325-330.

Choi, I. (2001). Unit root tests for panel data, Journal of International Money and Finance 20: 249-272.

Cuaresma, J. C. and Silgoner, M. A. (2004). Growth Effects of Inflation in Europe: How low is too low, how high is too high?, Working Paper University of Vienna .

Davidson, R. and MacKinnon, J. G. (1993). Estimation and Inference in Econometrics, Oxford University Press, New York.

Debelle, G. and Lamont, O. (1997). Relative Price Variability and Inflation: Evidence from U.S. Cities, Journal of Political Economy 105(1): 132-152.

ECB (2005). Diverse Patterns in Headline and Underlying Inflation, Monthly Bulletin November 2005: 36-40.

Fielding, D. and Mizen, P. (2000). Relative Price Variability and Inflation in Europe, Economica 67: 57-78.

Gali, J. (2003). New Perspectives on Monetary Policy, Inflation, and the Business Cycle, in M. Dewatripont, L. Hansen and S. Turnovsky (eds), Advances in Economic Theory, vol. III, Cambridge University Press, pp. 151-197. 
Green, E. J. (2005). A Review of Interest and Prices: Foundations of a Theory of Monetary Policy by Michael Woodford, Journal of Economic Literature XLIII: 121134.

Grier, K. B. and Perry, M. J. (1996). Inflation, Inflation Uncertainty, and the Relative Price Dispersion: Evidence from bivariate GARCH-M Models, Journal of Monetary Economics 38(2): 391-405.

Hansen, B. E. (1996). Inference when a Nuisance Parameter is not identified under the Null Hypothesis, Econometrica 64(2): 413-430.

Hansen, B. E. (1999). Threshold Effects in Non-Dynamic Panels: Estimation, Testing, and Inference, Journal of Econometrics 93: 345-368.

Hansen, B. E. (2000). Sample Splitting and Threshold Estimation, Econometrica 68(3): 575-603.

Hercowitz, Z. (1981). Money and the Dispersion of Relative Prices, Journal of Political Economy 89(2): 328-356.

Hondroyiannis, G. and Lazaretou, S. (2004). Inflation persistence during periods of structral change: an assessment using Greek data, ECB Working Paper 370.

Im, K., Pesaran, M. and Shin, Y. (2003). Testing for unit roots in heterogeneous panels, Journal of Econometrics 115: 53-74.

Jaramillo, C. (1999). Inflation and Relative Price Variability: Reinstating Parks' Results, Journal of Money, Credit, and Banking 31(3): 375-385.

Konieczny, J. D. and Skrzypacz, A. (2005). Inflation and Price Setting in a Natural Experiment, Journal of Monetary Economics 52: 621-632.

Levin, A., Lin, C. and Chu, C. (2002). Unit root tests in panel data: Asymptotic and finite-sample properties, Journal of Econometrics 108: 1-24. 
Lünnemann, P. and Mathä, T. Y. (2004). How persistent is disaggregate inflation? An analysis across EU15 countries and the HICP sub-indices, ECB Working Paper 415.

Maddala, G. S. and Wu, S. (1999). A comparative study of unit root tests with panel data and a new simple test, Oxford Bulletin of Economics and Statistics 61: 631652.

Nautz, D. and Scharff, J. (2005). Inflation and Relative Price Variability in a Low Inflation Country: Empirical Evidence for Germany, German Economic Review 6(4): $507-523$.

Parks, R. W. (1978). Inflation and Relative Price Variability, Journal of Political Economy 86(1): 79-95.

Parsley, D. C. (1996). Inflation and Relative Price Variability in the Short and Long Run: New Evidence from the United States, Journal of Money, Credit, and Banking 28(3): 323-341.

Rotemberg, J. J. (1983). Aggregate Consequences of Fixed Costs of Price Adjustment, American Economic Review 73(3): 433-436.

Sheshinski, E. and Weiss, Y. (1977). Inflation and Costs of Price Adjustment, Review of Economic Studies 44(2): 287-303.

Silver, M. and Ioannidis, C. (2001). Intercountry Differences in the Relationship between Relative Price Variability and Average Prices, Journal of Political Economy 109(2): $355-374$.

Tsionas, E. G. and Christopoulos, D. K. (2003). Maastricht convergence and real convergence: European evidence from threshold and smooth transition regression models, Journal of Policy Modeling 25: 43-52. 
Woodford, M. (2003). Interest and Prices: Foundations of a Theory of Monetary Policy, Princeton University Press, Princeton, New Jersey. 


\section{A Appendix}

\section{A.1 Data figures}

Figure 3: Headline inflation and RPV
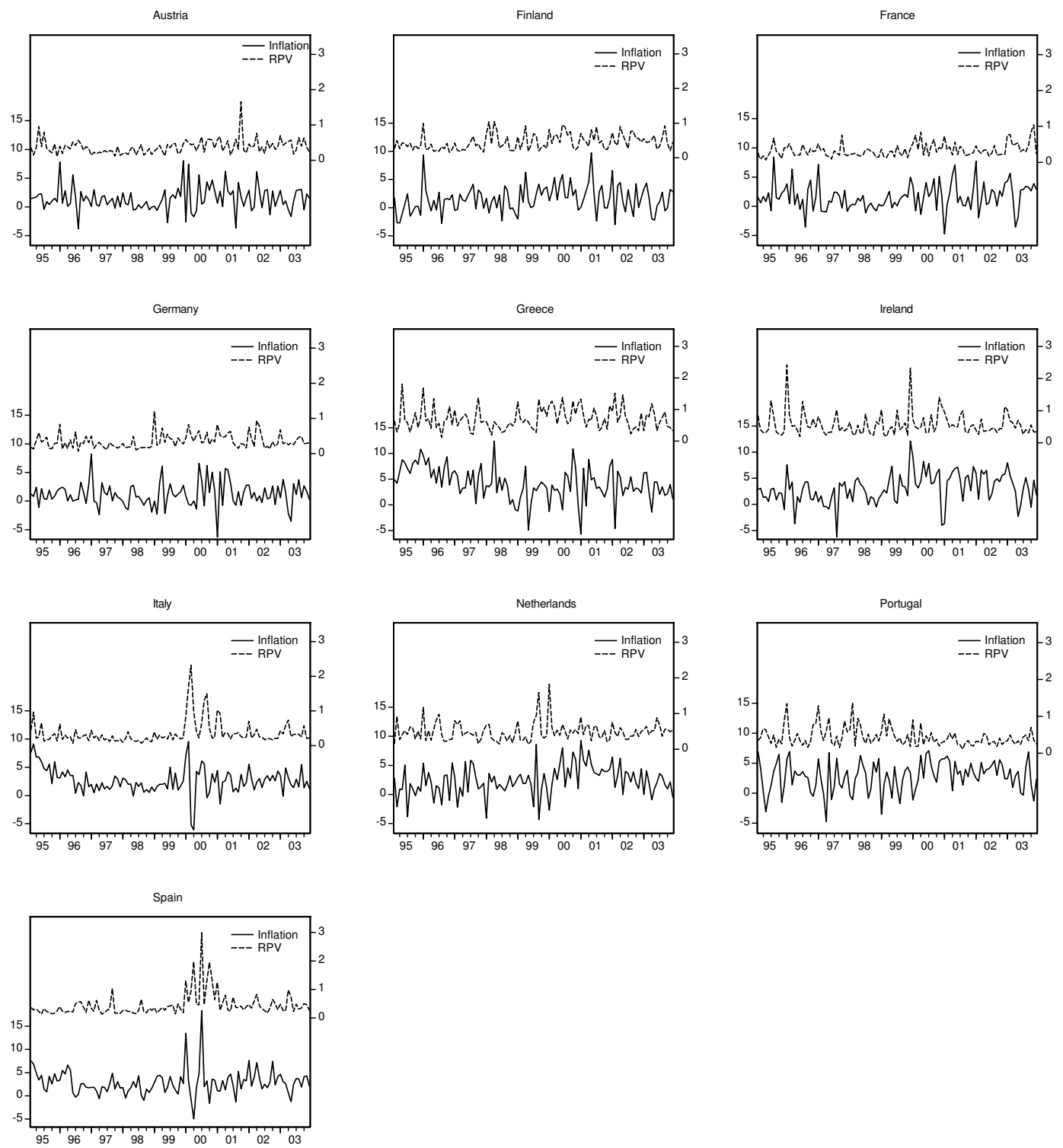

Notes: Annualized inflation rates and annualized RPV (percentage points, seasonally adjusted) confer to the harmonized index of consumer prices, 1995.02-2003.12. Source: Eurostat. 
Figure 4: Headline inflation and core inflation
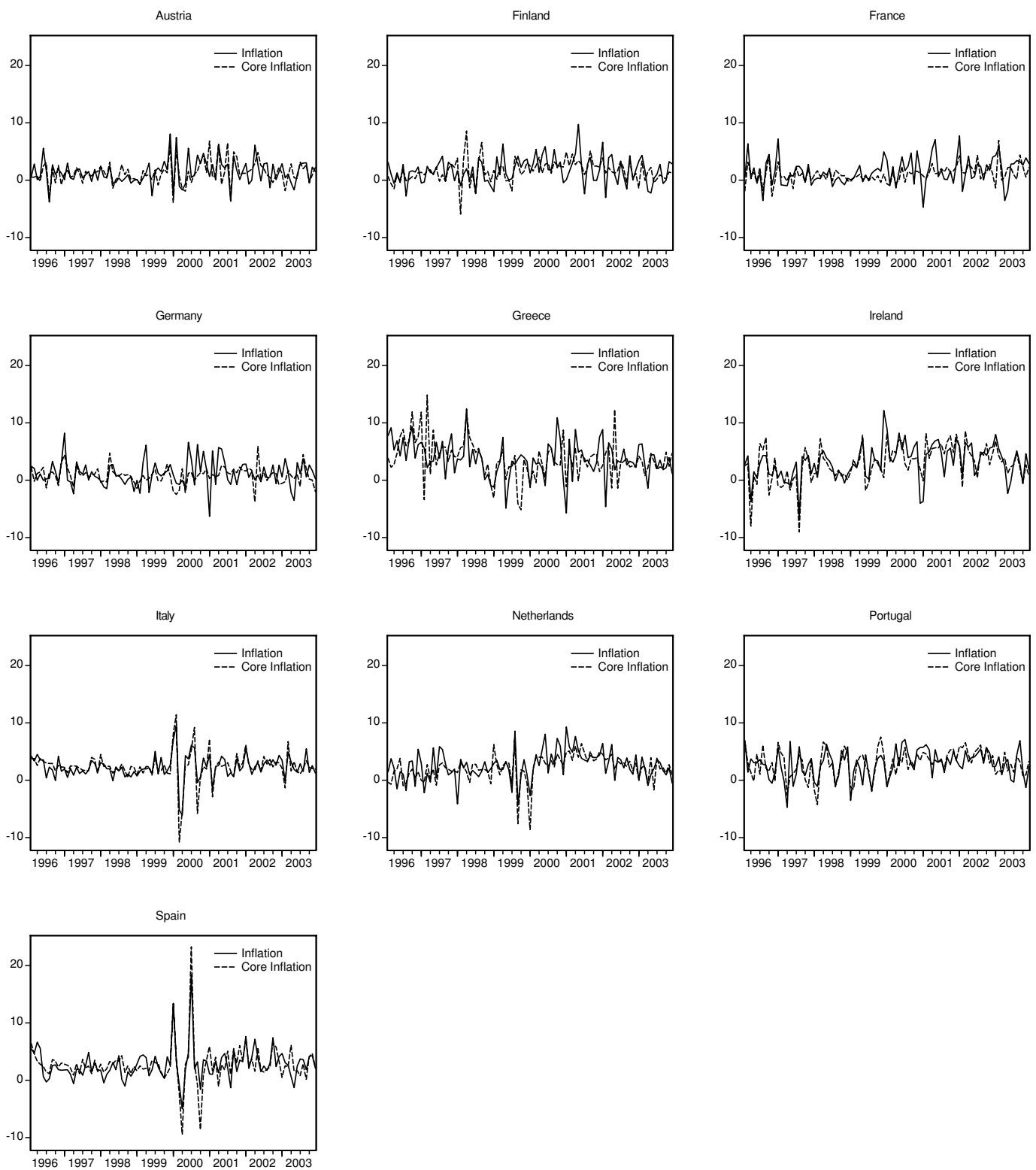

Notes: Annualized core inflation rates and annualized aggregate inflation (percentage points, seasonally adjusted) confer to the harmonized index of consumer prices, 1996.022003.12. Source: Eurostat. 
Figure 5: Distribution of national core inflation rates in the euro area

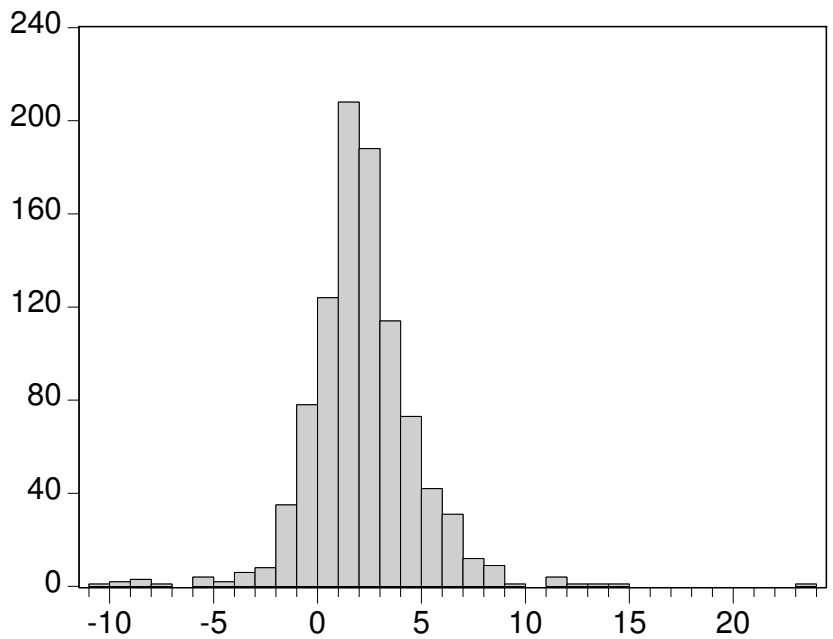

\begin{tabular}{|lr|}
\hline \multicolumn{2}{l}{ Annualized Core Inflation } \\
\multicolumn{2}{|l}{ Sample 1996.02-2003.12 } \\
(Observations 950) \\
Minimum & -10.79 \\
Maximum & 23.26 \\
Mean & 2.17 \\
Median & 2.02 \\
Lower Quartile & 0.86 \\
Upper Quartile & 3.38 \\
Std. Dev. & 2.64 \\
Skewness & 0.53 \\
Kurtosis & 10.38 \\
\hline
\end{tabular}

Notes: Annualized national core inflation rates (percentage points, seasonally adjusted) confer to the harmonized index of consumer prices, 1996.02-2003.12. Source: Eurostat.

Figure 6: Minimum and maximum of core inflation

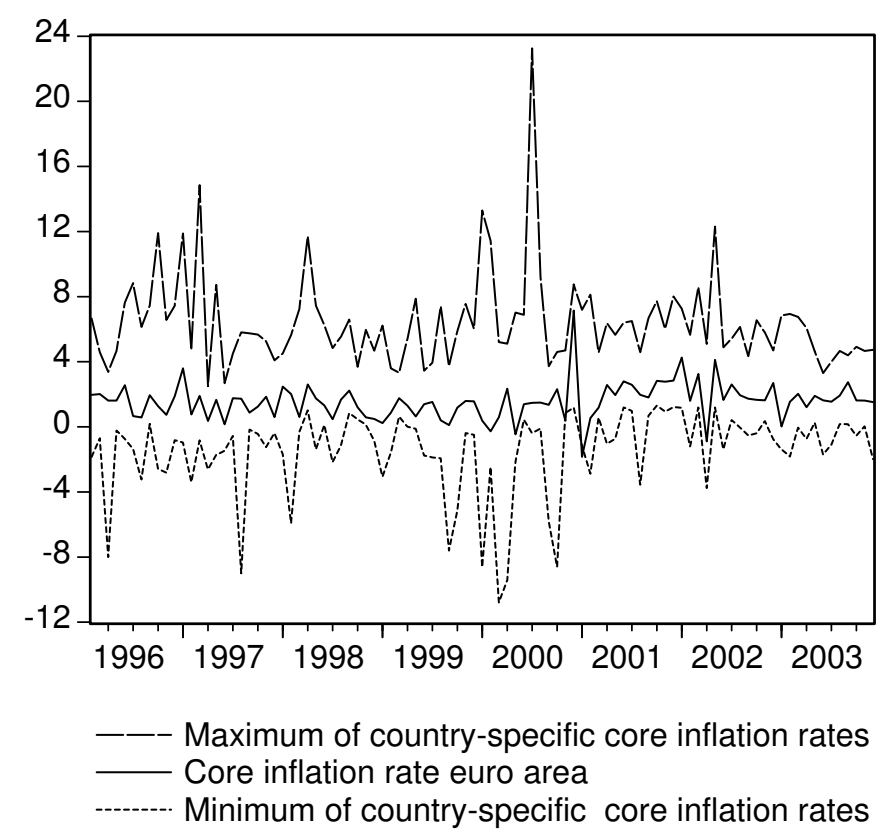

Notes: Annualized core inflation rates (percentage points, seasonally adjusted) confer to the harmonized index of consumer prices, 1995.02-2003.12. Source: Eurostat. The generated time series for minimum (maximum) core inflation show the minimum (maximum) of the national core inflation rates across the EMU members. 


\section{A.2 Tables}

\section{A.2.1 Panel unit root tests}

Table 5: Panel unit root tests

\begin{tabular}{lccc}
\hline & Inflation & Core Inflation & RPV \\
\hline$H_{0}$ : common unit root process & & & \\
Levin, Lin, Chu & -29.17 & -16.30 & -24.48 \\
& {$[0.00]$} & {$[0.00]$} & {$[0.00]$} \\
Breitung & -12.60 & -6.01 & -15.80 \\
$H_{0}$ : individual unit root process & {$[0.00]$} & {$[0.00]$} & {$[0.00]$} \\
Im, Pesaran, Shin & & & \\
ADF-Fisher & -25.89 & -17.74 & -22.39 \\
PP-Fisher & {$[0.00]$} & {$[0.00]$} & {$[0.00]$} \\
& {$[0.22$} & 210.82 & 427.14 \\
& 561.11 & {$[0.00]$} & {$[0.00]$} \\
& {$[0.00]$} & 290.24 & 495.61 \\
\end{tabular}

Notes: The Levin, Lin and Chu (2002) test and the Breitung (2000) test assume that there is a common unit root process under the null. Im, Pesaran and Shin (2003) as well as the Fisher-ADF and Fisher-Phillips-Perron test by Maddala and Wu (1999) and Choi (2001), respectively, allow for individual unit root processes. All tests choose the lags based on the Schwarz information criterion. In all tests there is clear evidence in form of stationarity of inflation, core inflation, and RPV. 


\section{A.2.2 Expected core inflation and headline inflation as threshold variable}

Table 6: Test for the number of thresholds with alternative threshold variables

$$
R P V_{i t}=\alpha_{i}+\sum_{k=0}^{K} \beta_{k+1}\left|\pi_{i t}^{e}\right| I\left(\gamma_{k}<x_{i t} \leq \gamma_{k+1}\right)+\delta\left|\pi_{i t}-\pi_{i t}^{e}\right|+\varepsilon_{i t}
$$

expected core inflation

headline inflation

\begin{tabular}{lrr}
\hline \hline$H_{0}:$ no threshold $(K=0)$ & & \\
$F_{1}$ & 71.56 & 84.05 \\
p-value & 0.00 & 0.00 \\
$(10 \%, 5 \%, 1 \%$ critical values $)$ & $(7.77,9.94,16.09)$ & $(7.93,9.66,15.03)$ \\
\hline$H_{0}:$ at most one threshold $(K=1)$ & & \\
$F_{2}$ & 12.80 & 61.09 \\
p-value & 0.01 & 0.00 \\
$(10 \%, 5 \%, 1 \%$ critical values $)$ & $(8.45,9.71,12.43)$ & $(8.15,9.63,13.98)$ \\
\hline$H_{0}:$ at most two thresholds $(K=2)$ & & \\
$F_{3}$ & 5.28 & 2.66 \\
p-value & 0.54 & 0.73 \\
$(10 \%, 5 \%, 1 \%$ critical values $)$ & $(9.12,10.75,13.78)$ & $(7.59,9.03,13.40)$ \\
\hline
\end{tabular}

Notes: The threshold variable $x_{i t}$ is monthly expected core inflation or monthly headline inflation. 1000 bootstrap replications were used to obtain the p-values. $\gamma_{0}=-\infty, \gamma_{K+1}=\infty$. The sequential test procedure indicates that the number of thresholds for both expected core inflation and headline inflation is $K=2$. 
Table 7: A double threshold model with alternative threshold variables

\begin{tabular}{|c|c|c|}
\hline \multicolumn{3}{|c|}{$R P V_{i t}=\alpha_{i}+\beta_{1}\left|\pi_{i t}^{e}\right| I\left(x_{i t} \leq \gamma_{1}\right)+\beta_{2}\left|\pi_{i t}^{e}\right| I\left(\gamma_{1}<x_{i t} \leq \gamma_{2}\right)+\beta_{3}\left|\pi_{i t}^{e}\right| I\left(\gamma_{2}<x_{i t}\right)+\delta\left|\pi_{i t}-\pi_{i t}^{e}\right|+\varepsilon_{i t}$} \\
\hline & expected core inflation & headline inflation \\
\hline \multicolumn{3}{|l|}{ Threshold estimates } \\
\hline$\widehat{\gamma}_{1}$ & 0.0441 & -0.0887 \\
\hline $95 \%$ confidence interval & {$[0.0047,0.0541]$} & {$[-0.0972,-0.0777]$} \\
\hline$\widehat{\gamma}_{2}$ & 0.3671 & 0.4687 \\
\hline $95 \%$ confidence interval & {$[0.1662,0.3854]$} & {$[0.4655,0.4694]$} \\
\hline \multicolumn{3}{|l|}{ Regression estimates } \\
\hline$\widehat{\beta}_{1}$ & $\begin{array}{l}1.86^{* *} \\
(0.22)\end{array}$ & $\begin{array}{l}1.60^{* *} \\
(0.17)\end{array}$ \\
\hline$\widehat{\beta}_{2}$ & $\begin{array}{r}-0.09 \\
(0.11)\end{array}$ & $\begin{array}{r}-0.08 \\
(0.09)\end{array}$ \\
\hline$\widehat{\beta}_{3}$ & $\begin{array}{l}0.26^{* *} \\
(0.09)\end{array}$ & $\begin{array}{l}0.66^{* *} \\
(0.11)\end{array}$ \\
\hline$\widehat{\delta}$ & $\begin{array}{l}1.04^{* *} \\
(0.07)\end{array}$ & $\begin{array}{l}0.97^{* *} \\
(0.07)\end{array}$ \\
\hline SSR & 46.79 & 43.62 \\
\hline Observations in regime 1 & 81 & 59 \\
\hline Observations in regime 2 & 697 & 691 \\
\hline Observations in regime 3 & 52 & 80 \\
\hline
\end{tabular}

Notes: The threshold variable $x_{i t}$ is monthly expected core inflation or monthly headline inflation. Standard errors are given in parentheses, p-values in brackets. ${ }^{* *}$ indicate significance at the $1 \%$ level. 


\section{A.2.3 Unexpected inflation as threshold variable}

Table 8: Test procedure establishing the number of thresholds for expected inflation

$$
R P V_{i t}=\alpha_{i}+\sum_{k=0}^{K} \beta_{k+1}\left|\pi_{i t}^{e}\right| I\left(\gamma_{k}<\left(\pi_{i t}-\pi_{i t}^{e}\right) \leq \gamma_{k+1}\right)+\delta\left|\pi_{i t}-\pi_{i t}^{e}\right|+\varepsilon_{i t}
$$

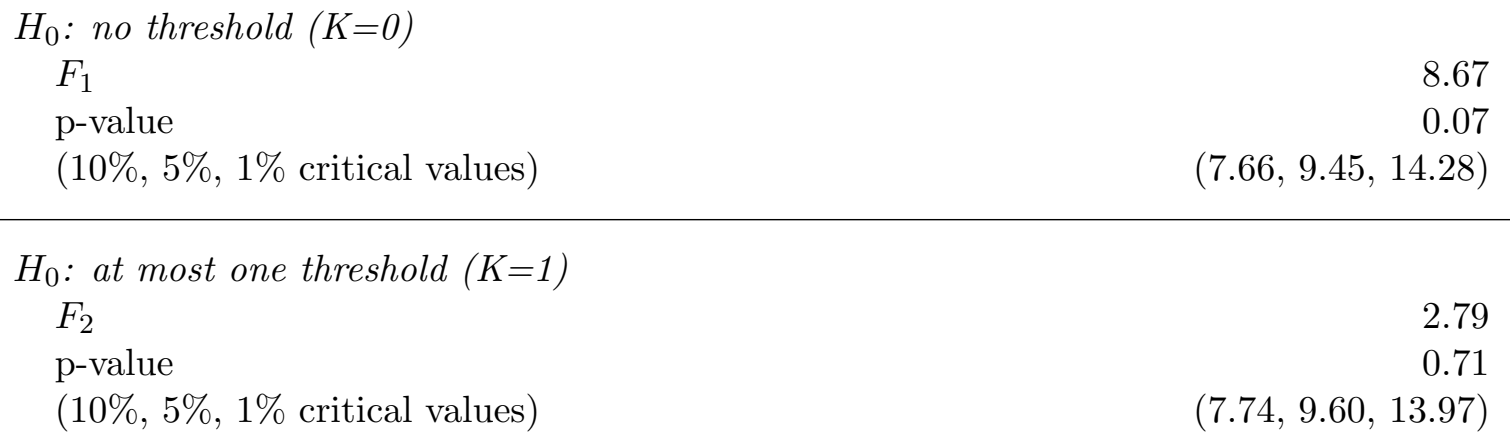

Notes: The threshold variable is unexpected inflation. 1000 bootstrap replications were used to obtain the p-values. $\gamma_{0}=-\infty, \gamma_{K+1}=\infty$. The sequential test procedure indicates that there is no threshold $(K=0)$.

Table 9: Test procedure establishing the number of thresholds for unexpected inflation

$$
\begin{aligned}
R P V_{i t}= & \alpha_{i}+\beta_{1}\left|\pi_{i t}^{e}\right| I\left(\pi_{i t} \leq-0.11\right)+\beta_{2}\left|\pi_{i t}^{e}\right| I\left(-0.11<\pi_{i t} \leq 0.49\right)+\beta_{3}\left|\pi_{i t}^{e}\right| I\left(0.49<\pi_{i t}\right) \\
& +\sum_{k=0}^{K} \delta_{k+1}\left|\pi_{i t}-\pi_{i t}^{e}\right| I\left(\gamma_{k}<\left(\pi_{i t}-\pi_{i t}^{e}\right) \leq \gamma_{k+1}\right)+\varepsilon_{i t}
\end{aligned}
$$

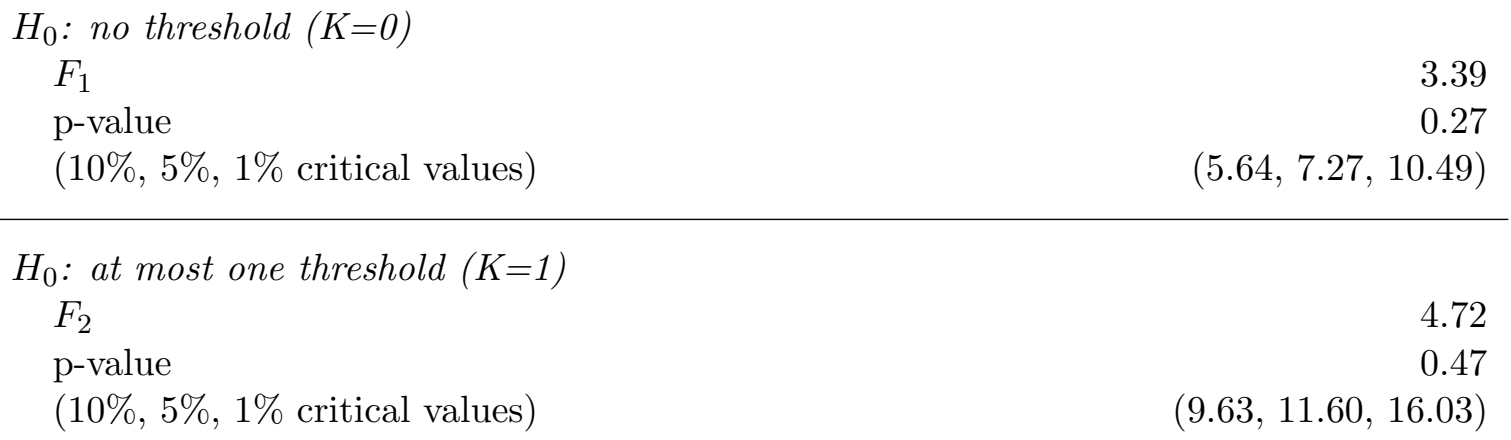

Notes: The threshold variable is unexpected inflation. 1000 bootstrap replications were used to obtain the p-values. $\gamma_{0}=-\infty, \gamma_{K+1}=\infty$. The sequential test procedure indicates that there is no threshold $(K=0)$. 


\section{The following Discussion Papers have been published since 2005:}

\section{Series 1: Economic Studies}

12005 Financial constraints and capacity adjustment in the United Kingdom - Evidence from a Ulf von Kalckreuth large panel of survey data Emma Murphy

22005 Common stationary and non-stationary factors in the euro area analyzed in a large-scale factor model

Sandra Eickmeier

32005 Financial intermediaries, markets, F. Fecht, K. Huang, and growth

A. Martin

42005 The New Keynesian Phillips Curve in Europe: does it fit or does it fail?

Peter Tillmann

52005 Taxes and the financial structure

Fred Ramb

of German inward FDI

A. J. Weichenrieder

62005 International diversification at home

Fang Cai and abroad

Francis E. Warnock

72005 Multinational enterprises, international trade, and productivity growth: Firm-level evidence from the United States

Wolfgang Keller Steven R. Yeaple

82005 Location choice and employment

S. O. Becker, decisions: a comparison of German K. Ekholm, R. Jäckle, and Swedish multinationals M.-A. Muendler

92005 Business cycles and FDI:

Claudia M. Buch

evidence from German sectoral data

Alexander Lipponer

102005 Multinational firms, exclusivity,

Ping Lin and the degree of backward linkages

Kamal Saggi 
112005 Firm-level evidence on international stock market comovement

122005 The determinants of intra-firm trade: in search for export-import magnification effects

132005 Foreign direct investment, spillovers and absorptive capacity: evidence from quantile regressions

142005 Learning on the quick and cheap: gains from trade through imported expertise
Robin Brooks Marco Del Negro

Peter Egger

Michael Pfaffermayr

Sourafel Girma

Holger Görg

James R. Markusen

Thomas F. Rutherford

152005 Discriminatory auctions with seller discretion:

evidence from German treasury auctions Jörg Rocholl

162005 Consumption, wealth and business cycles:

B. Hamburg, why is Germany different?

M. Hoffmann, J. Keller

172005 Tax incentives and the location of FDI:

Thiess Buettner

evidence from a panel of German multinationals Martin Ruf

182005 Monetary Disequilibria and the

Dieter Nautz

Euro/Dollar Exchange Rate

Karsten Ruth

$192005 \quad$ Berechnung trendbereinigter Indikatoren für

Deutschland mit Hilfe von Filterverfahren

Stefan Stamfort

202005 How synchronized are central and east

European economies with the euro area?

Sandra Eickmeier

Evidence from a structural factor model

Jörg Breitung

212005 Asymptotic distribution of linear unbiased

J.-R. Kurz-Kim

estimators in the presence of heavy-tailed

S.T. Rachev

stochastic regressors and residuals

G. Samorodnitsky 
222005 The Role of Contracting Schemes for the Welfare Costs of Nominal Rigidities over the Business Cycle Matthias Paustian

232005 The cross-sectional dynamics of German

J. Döpke, M. Funke business cycles: a bird's eye view

S. Holly, S. Weber

$24 \quad 2005 \quad$ Forecasting German GDP using alternative

Christian Schumacher factor models based on large datasets

252005 Time-dependent or state-dependent price setting? - micro-evidence from German metal-working industries -

Harald Stahl

262005 Money demand and macroeconomic

Claus Greiber uncertainty

Wolfgang Lemke

$27 \quad 2005 \quad$ In search of distress risk

J. Y. Campbell,

J. Hilscher, J. Szilagyi

282005 Recursive robust estimation and control

Lars Peter Hansen

without commitment

Thomas J. Sargent

$292005 \quad$ Asset pricing implications of Pareto optimality

N. R. Kocherlakota

with private information

Luigi Pistaferri

$302005 \quad$ Ultra high frequency volatility estimation

Y. Aït-Sahalia,

with dependent microstructure noise

P. A. Mykland, L. Zhang

$312005 \quad$ Umstellung der deutschen VGR auf Vorjahrespreisbasis - Konzept und Konsequenzen für die aktuelle Wirtschaftsanalyse sowie die ökonometrische Modellierung

Karl-Heinz Tödter 
$32 \quad 2005$ Determinants of current account developments in the central and east European EU member states - consequences for the enlargement of the euro erea

Sabine Herrmann

Axel Jochem

332005 An estimated DSGE model for the German economy within the euro area

Ernest Pytlarczyk

342005 Rational inattention: a research agenda

Christopher A. Sims

352005 Monetary policy with model uncertainty:

Lars E.O. Svensson distribution forecast targeting Noah Williams

362005 Comparing the value revelance of $R \& D$ report- Fred Ramb ing in Germany: standard and selection effects Markus Reitzig

$372005 \quad$ European inflation expectations dynamics

J. Döpke, J. Dovern

U. Fritsche, J. Slacalek

$38 \quad 2005 \quad$ Dynamic factor models

Sandra Eickmeier

Jörg Breitung

$392005 \quad$ Short-run and long-run comovement of GDP and some expenditure aggregates in Germany, France and Italy

Thomas A. Knetsch

$402005 \quad$ A "wreckers theory" of financial distress

Ulf von Kalckreuth

412005 Trade balances of the central and east European EU member states and the role of foreign direct investment

Sabine Herrmann Axel Jochem

$42 \quad 2005 \quad$ Unit roots and cointegration in panels Jörg Breitung M. Hashem Pesaran

432005 Price setting in German manufacturing: new evidence from new survey data Harald Stahl 
12006 The dynamic relationship between the Euro overnight rate, the ECB's policy rate and the term spread

Dieter Nautz

Christian J. Offermanns

22006 Sticky prices in the euro area: a summary of new micro evidence

Álvarez, Dhyne, Hoeberichts

Kwapil, Le Bihan, Lünnemann

Martins, Sabbatini, Stahl

Vermeulen, Vilmunen

32006 Going multinational: What are the effects on home market performance? Robert Jäckle

42006 Exports versus FDI in German manufacturing: firm performance and participation in inter- Jens Matthias Arnold national markets

Katrin Hussinger

52006 A disaggregated framework for the analysis of

Kremer, Braz, Brosens structural developments in public finances Langenus, Momigliano Spolander

62006 Bond pricing when the short term interest rate Wolfgang Lemke follows a threshold process Theofanis Archontakis

72006 Has the impact of key determinants of German exports changed?

Results from estimations of Germany's intra euro-area and extra euro-area exports

Kerstin Stahn

82006 The coordination channel of foreign exchange Stefan Reitz intervention: a nonlinear microstructural analysis Mark P. Taylor

92006 Capital, labour and productivity: What role do Antonio Bassanetti they play in the potential GDP weakness of Jörg Döpke, Roberto Torrini France, Germany and Italy? Roberta Zizza

102006 Real-time macroeconomic data and ex ante

J. Döpke, D. Hartmann predictability of stock returns

C. Pierdzioch 
112006 The role of real wage rigidity and labor market frictions for unemployment and inflation Kai Christoffel dynamics

Tobias Linzert

$122006 \quad$ Forecasting the price of crude oil via convenience yield predictions

Thomas A. Knetsch

132006 Foreign direct investment in the enlarged EU: do taxes matter and to what extent? Guntram B. Wolff

142006 Inflation and relative price variability in the euro Dieter Nautz area: evidence from a panel threshold model Juliane Scharff 


\section{Series 2: Banking and Financial Studies}

12005 Measurement matters - Input price proxies and bank efficiency in Germany

Michael Koetter

22005 The supervisor's portfolio: the market price risk of German banks from 2001 to 2003 Analysis and models for risk aggregation

Christoph Memmel

Carsten Wehn

$32005 \quad$ Do banks diversify loan portfolios?

Andreas Kamp

A tentative answer based on individual

Andreas Pfingsten

bank loan portfolios

Daniel Porath

42005 Banks, markets, and efficiency

F. Fecht, A. Martin

52005 The forecast ability of risk-neutral densities

Ben Craig of foreign exchange

Joachim Keller

62005 Cyclical implications of minimum capital requirements

Frank Heid

72005 Banks' regulatory capital buffer and the business cycle: evidence for German savings and cooperative banks

Stéphanie Stolz

Michael Wedow

82005 German bank lending to industrial and nonindustrial countries: driven by fundamentals or different treatment?

Thorsten Nestmann

92005 Accounting for distress in bank mergers

M. Koetter, J. Bos, F. Heid

C. Kool, J. Kolari, D. Porath

102005 The eurosystem money market auctions:

Nikolaus Bartzsch a banking perspective

Ben Craig, Falko Fecht

$112005 \quad$ Financial integration and systemic

Falko Fecht risk

Hans Peter Grüner 
$12 \quad 2005$ Evaluating the German bank merger wave

132005 Incorporating prediction and estimation risk in point-in-time credit portfolio models

142005 Time series properties of a rating system based on financial ratios

$152005 \quad$ Inefficient or just different? Effects of heterogeneity on bank efficiency scores

$012006 \quad$ Forecasting stock market volatility with macroeconomic variables in real time
Michael Koetter
A. Hamerle, M. Knapp,
T. Liebig, N. Wildenauer

U. Krüger, M. Stötzel,

S. Trück

J. Bos, F. Heid, M. Koetter,

J. Kolatri, C. Kool

J. Döpke, D. Hartmann

C. Pierdzioch 


\section{Visiting researcher at the Deutsche Bundesbank}

The Deutsche Bundesbank in Frankfurt is looking for a visiting researcher. Among others under certain conditions visiting researchers have access to a wide range of data in the Bundesbank. They include micro data on firms and banks not available in the public. Visitors should prepare a research project during their stay at the Bundesbank. Candidates must hold a $\mathrm{Ph} \mathrm{D}$ and be engaged in the field of either macroeconomics and monetary economics, financial markets or international economics. Proposed research projects should be from these fields. The visiting term will be from 3 to 6 months. Salary is commensurate with experience.

Applicants are requested to send a $\mathrm{CV}$, copies of recent papers, letters of reference and a proposal for a research project to:

Deutsche Bundesbank

Personalabteilung

Wilhelm-Epstein-Str. 14

D - 60431 Frankfurt

GERMANY 


